\title{
A Vulnerable Environment Study in Karst Regions between 1991 and 2017: A Bibliometric Analysis
}

\author{
Pengtao Shi ${ }^{1,2,+}$, Tianshu Zhang ${ }^{3,4,+}$, Ziqi Liu ${ }^{1,2, *}$, Jiacheng Lan ${ }^{1,2}$ and Xin Fan ${ }^{5}$ \\ 1 School of Karst Science, Guizhou Normal University, Guiyang 550001, China; shipt1992@gznu.edu.cn (P.S.); \\ lanjiacheng@gznu.edu.cn (J.L.) \\ 2 State Engineering Technology Institute for Karst Desertification Control, Guiyang 550001, China \\ 3 Department of Earth Sciences, Zhejiang University, Hangzhou 310027, China; 11538009@zju.edu.cn \\ 4 Department of Geography \& Anthropology, Louisiana State University, Baton Rouge, LA 70803, USA \\ 5 School of Public Administration, China University of Geosciences (Wuhan), Wuhan 430074, China; \\ 2013100026@cug.edu.cn \\ * Correspondence: 201511004@gznu.edu.cn \\ $\dagger$ These authors contributed equally to this work and should be considered co-first authors.
}

Received: 5 November 2019; Accepted: 3 December 2019; Published: 6 December 2019

\begin{abstract}
In order to understand the research hotspots and the development directions in the field of vulnerable karst environment, we undertook bibliometrics citation analysis on 5425 contributions to the literature written in the range from 1991 to 2017 based on the "Web of Science" core collection citation index database. Hopefully, this work will help to set up a scientific foundation for further studies. This research considered the following factors: keywords frequency, influence of author, research hotspot, reference citation network, research institution and the evolution of research topic. It was revealed that the research interests were focused on water, cave, and soil environments and implicated trends switching from a water environment to cave and eco-environment and from ecological restoration and rehabilitation to karst rocky desertification. A European-American-Chinese centered cooperation network has shown its initial form. This research will offer researchers a bird's eye view of the global vulnerable karst environment and point out the directions of further study.
\end{abstract}

Keywords: bibliometric analysis; literature review; vulnerable environment; karst regions

\section{Introduction}

Karst environment, the most vulnerable natural environment in the world, is easily influenced by human activities that have caused many environmental problems, such as environment degradation and disruption, and resulted in high economic cost [1-3]. The environmental degradation and disruption are characterized by drought, flood, soil erosion, reduction of vegetation coverage, rocky desertification, surface subsidence, loss of biodiversity, habitat fragmentation, changes in physiological and ecological characteristics of plant communities, pollution and depletion of water resources, and the accompanied poverty. The vulnerable environment with its attenuated sustainable development ability cannot adapt to the fast-paced social and economic development [1,4-8].

Currently, the understanding of the vulnerability of karst environment has reached a new height, which greatly facilitated the settlement of the degradation and pollution problems [5,9-14].

Karst systems are highly dynamic and heterogeneous. The complicate hydrological, geochemical, and biological processes have great impact on the transfer of water, solute, and non-aqueous substance on large-scale spatial and temporal scale [15]. Meanwhile, the distribution of animals and plants and the activities of human beings are also greatly impacted by the hydrological network, rock solubility, and the unique landscape of karst systems [16]. However, the karst regions are faced with increasing 
pressure of ecological degradation due to the increasing population and demands of resources and the vulnerability of surface soil [14,17-20]. The formation and development of vulnerable karst environment are tightly connected with human activities, especially in developing countries. It has caused the deterioration of ecosystem services and ultimately forced local residents to live in greater poverty $[4,17,20-22]$.

In the past few years, a lot of researches about vulnerable karst environment have been undertaken. Some of the researches covered areas of characteristics of vulnerable karst environment, cause of formation, and ecological restoration and rehabilitation [11,20,23-26], while others focused on the landscape of karst rocky desertification $[5,10,18,19,27]$, the soil erosion in karst region [9,28-31], cave environment [32-34], aquifer and spring based water environment [35-45], carbon source and sink [46-48], eco-hydrology [49,50], and protection and management of vulnerable karst environment $[13,51,52]$. Those researches addressed the major issues, yet there is still a lack of a general review that may reveal the trend of studies in this field. This paper gives a comprehensive analysis, from the angle of biliometrics, in the field of vulnerable karst environment and provides insights for further studies.

This work helps to define the research clusters and researchers with a stronger impact on the field by identifying the mature and emerging research topics online using bibliometrics tools. Bibliometric analysis revealed the interests and new topics in the field and pointed out the possible directions of future studies [53]. Although the importance of researches on vulnerable karst environment has been increasingly emphasized, there is no bibliometric analysis popped up into our sight of searching. This work summarized the knowledge foundation and research frontiers in the field of vulnerable karst environment through bibliometric analysis on the literature in the "Web of Science" database from 1991 to 2017. It clarified current research hotspots and future research directions and provided scientific foundation for further studies in this field.

\section{Data and Methods}

Bibliometrics is a statistical method used for evaluating and quantifying the course of development, research focus, and future development trend in a research field. It uses document system and bibliometric characteristics as the objects of study. By quantitatively analyzing the distribution structure, quantity relation, and number rule of a document system with statistical and mathematical methods, bibliometrics provided a useful tool of systematically studying the research progress in a specific field [54]. Bibliometrics has drawn much attention as it enabled researchers to extract precious information about research progress in a specific research field $[55,56]$.

\subsection{Research Questions}

In order to better understand the research progress in the field of vulnerable karst environment, we used bibliometric methods and referred to the research methods of Kitchenman et al. [57], Petersen et al. [58], Marcos-Pablos et al. [59] and García-González et al. [60]. By employing a variety of visualization software, such as CiteSpace [61], Carrot2 [62], VOSViewer [63], CartoDB [64], and Google Earth (http://earth.google.com), we performed visual recognition, keywords co-occurrence analysis, author influence analysis, and literature co citation analysis; revealed the research frontier; summarized the research status; clarified the research hotspots and evolution trends. In this article, we answered the following questions:

(1) What are the general characteristics of the study in the field of vulnerable karst environment?

(2) Who are the significant authors in the field?

(3) Who are the authors having the highest co-citation rate?

(4) What is the global distribution of the main research institutions?

(5) What are the research hotspots and trends in this field? 


\subsection{Appropriately Define Searching Criteria}

Based on the knowledge about the vulnerable karst environment, in this work, the key indexing rules were set as: ("karst" or "karstification" or "karstic" or "epikarst") AND ("ecolog*" or "ecosystem*" or "environment ${ }^{* "}$ or "frail "* or "vulnerab*" or "restoration" or "degradation" or "rehabilitation" or "deterioration" or "compensation" or "loss" or "leakage" or "erosion" or "desertifi*" or "exposed bedrock" or "bare rock" or "bedrock bareness" or "vegetation recovery" or "evaluat" or "evolution*" or "instab" or "sensitiv" or "fragility"), * represents a wildcard. For this study, we analyzed the research papers about vulnerable karst environment and applied the following inclusion criteria:

(1) The keywords were selected to ensure the full coverage of researches in the field of vulnerable karst environment research.

(2) Articles that can be retrieved by the Web of Science database.

(3) Articles were written in English.

(4) SCI/SSCI articles only.

(5) Articles published before 2018.

\subsection{Preliminary Searching Results}

The "Web of Science" (WOS) core collection citation index database is the most frequently used database in bibliometric studies. We used "subject" retrieval in "Science Citation Index Expanded (SCI-EXPANDED)" and "Social Sciences Citation Index (SSCI)" databases from January to August in 2018. In order to get more stable results, we conducted the research for the whole year. The document type was set as "article" and the time range was set from 1900 to 2017. There were 7504 articles in the preliminary searching results (see Table 1 for more details). The searching results were saved as RIS format, which included important information such as title, author, subordinate relationship, abstract, keywords, and citation.

Table 1. The preliminary search results.

\begin{tabular}{cccc}
\hline Searching Results & $\begin{array}{c}\text { Total Citation } \\
\text { Frequency }\end{array}$ & $\begin{array}{c}\text { Average Citation } \\
\text { Frequency }\end{array}$ & H-Index \\
\hline 7504 & 121,156 & 16.15 & 103 \\
\hline
\end{tabular}

\subsection{Optimization of Searching Results}

Based on keywords co-occurrence analysis and keywords burst change analysis (Figures 1 and 2), the reasonability and accuracy of the keywords were verified. We found that the results of preliminary search are complicated and must be refined, so we applied the following exclusion criteria:

(1) Unrelated articles

(2) Repeated articles

(3) Articles published not in the time range we specified

The unrelated keywords, such as "pice*", "abies", "1 karst", "spruce", "papyraceum", "ganoderma", "Haematoxylum", "Fomitopsis", "P. KARST", "ex-fr karst", "fr karst", "puteana", "Uwe Karst", "pine", "Inonotus", "Bjerkandera", "Postia caesia (Schrad. Fr.) P. Karst", and "gloeophyllum-sepiarium-(WULF) Karst" were removed. The searching criteria was revised as subject: ("karst" or "karstification" or "karstic" or "epikarst") AND subject: ("ecolog*" or "ecosystem*" or "environment" or "frail" or "vulnerab" or "restoration" or "degradation" or "rehabilitation" or "deterioration" or "compensation" or "loss" or "leakage" or "erosion" or "desertifi*" or "exposed bedrock" or "bare rock" or "bedrock bareness" or "vegetation recovery" or "evaluat" or "evolution*" or "instab" or "sensitiv*" or "fragility") NOT subject: ("pice*" or "abies" or "1 karst" or "spruce" or "papyraceum" or "ganoderma" or "Haematoxylum" or "Fomitopsis" or "P. KARST" or "ex-fr karst" or 
"fr karst" or "puteana" or "Uwe Karst" or "pine" or "Inonotus" or "Bjerkandera" or "Postia caesia (Schrad. Fr.) P. Karst" or "gloeophyllum-sepiarium-(WULF) Karst") AND document type: (Article). A total of 5431 articles were retrieved in the time range of the year from 1900 to 2017. After removing the repeated ones in Citespace, there were 5425 articles left (Table 2). The useful information such as author name, institution, keywords, year of publication, region of publication, and references were then extracted and saved.

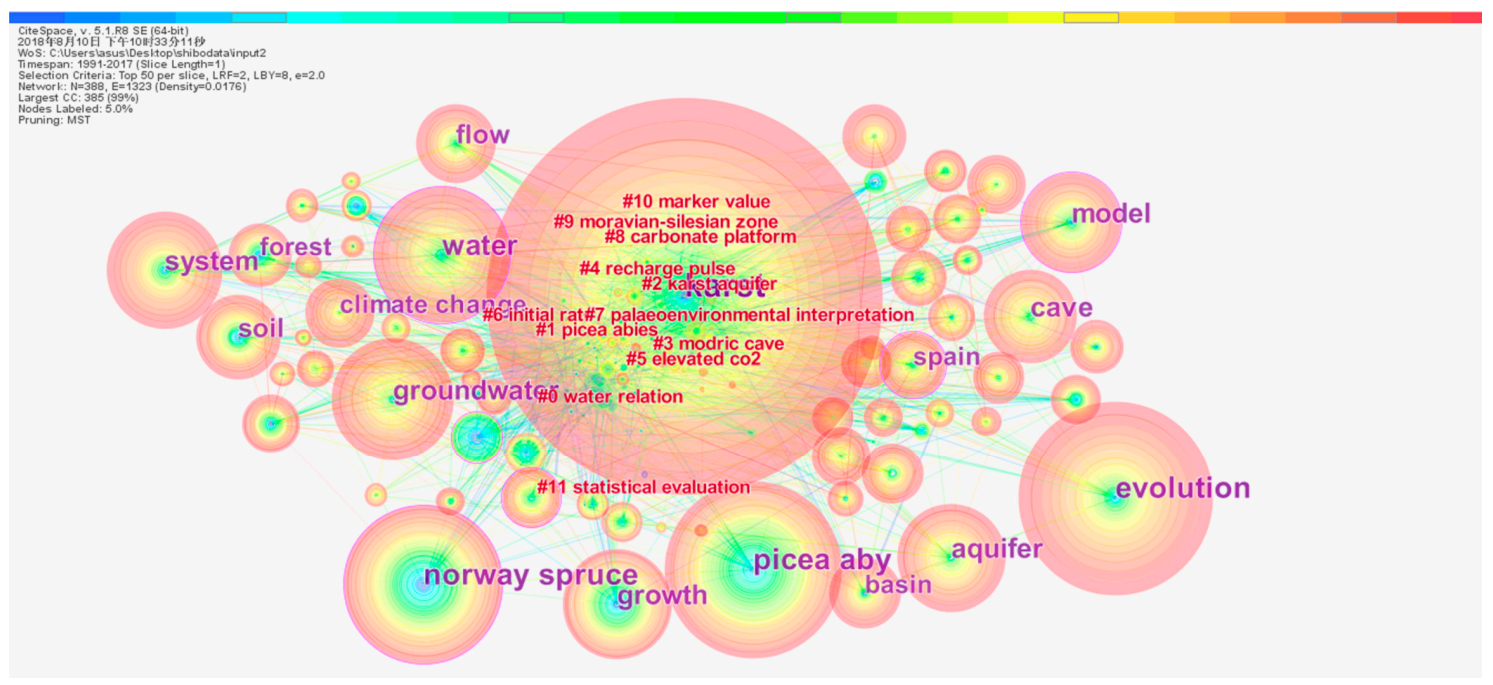

Figure 1. The keywords co-occurrence analysis of preliminary search results.

\section{Top 30 Keywords with the Strongest Citation Bursts}

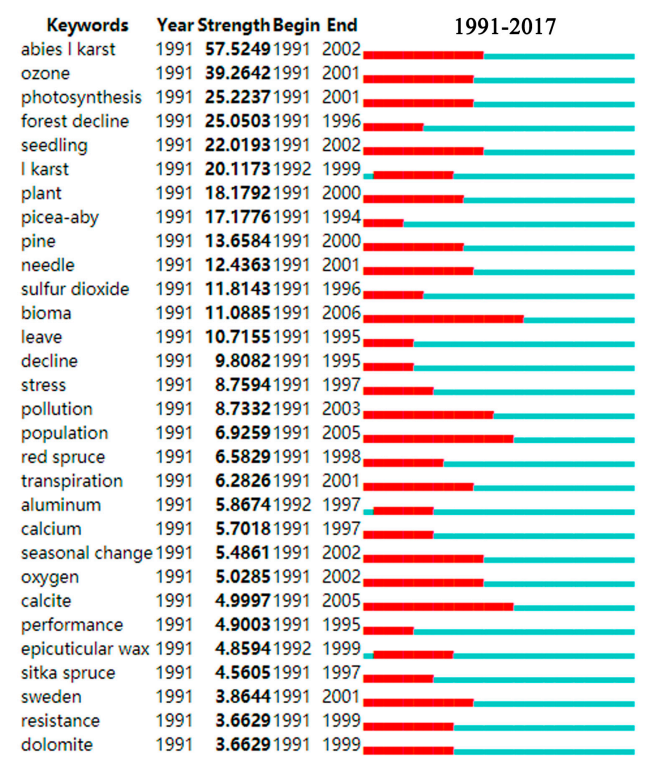

Figure 2. Top 30 Keywords with the strongest citation bursts of preliminary search results.

Table 2. The preliminary search results.

\begin{tabular}{ccccc}
\hline $\begin{array}{c}\text { Searching } \\
\text { Results }\end{array}$ & $\begin{array}{c}\text { Total Citation } \\
\text { Frequency }\end{array}$ & $\begin{array}{c}\text { Average Citation } \\
\text { Frequency }\end{array}$ & H-Index & $\begin{array}{c}\text { Number of Literatures after } \\
\text { Removing the Repeated Ones }\end{array}$ \\
\hline 5431 & 73,517 & 13.54 & 81 & 5425 \\
\hline
\end{tabular}




\subsection{Statistics}

The first article about vulnerable karst environment in the database of Web of Science can be traced back to 1965 (Figure 3). From 1965 to 2017, the amount of publications in the field increased steadily. Since there were only 54 articles published before 1991, accounting for $0.095 \%$, we can safely remove this part and focus our attention on the articles published in the range of the year from 1991 to 2017.

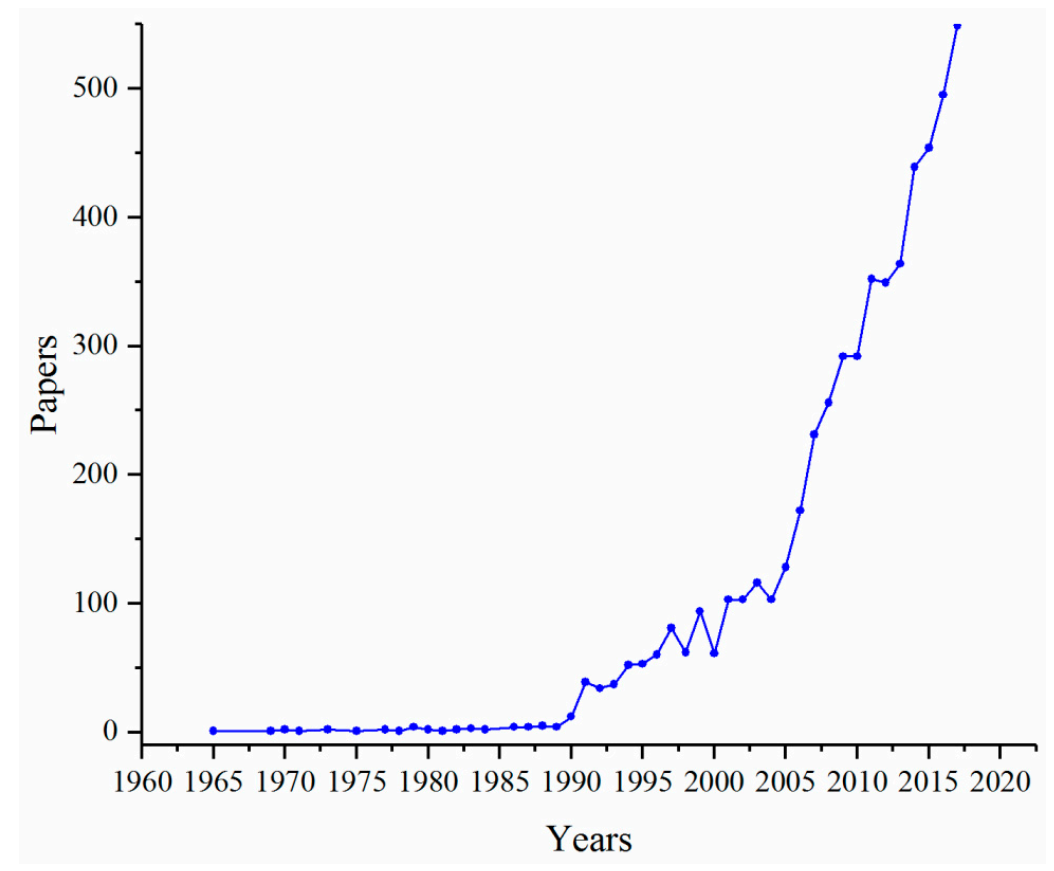

Figure 3. Publishing trend in the area of "vulnerable karst environment".

\subsection{Content Analysis Method}

In this paper, the key words, authors, organizations and regions of vulnerable karst environment are studied from a macro perspective, and on this basis, the future development trend is prospected. After visualization analysis with data network via using CiteSpace, Carrot2, VOSViewer softwares, the global scientific achievements in the field of vulnerable karst environment were mainly described from the following aspects:

(1) Analysis of author keywords;

(2) Analysis of author's influence;

(3) Analysis of research hotspots;

(4) Analysis of reference network;

(5) Geographical visualization analysis of research institutions;

(6) Analysis of the evolution of research topics;

(7) Analysis of major cooperative networks.

The main purpose of this work is to understand the research characteristics and subject areas in the field of vulnerable karst environment and provide insights for the future possible research directions in the field.

\section{Results and Discussion}

\subsection{Author Keywords Analysis}

The co-occurrence relation of the keywords of SCI/SSCI journal articles about "vulnerable karst environment" (Figure 4) was analyzed and the result showed that the research interests were focused 
on the following areas: (1) The frequent occurrence of the keywords related to karst water environment, such as "groundwater", "karst aquifer", and "spring", indicated that karst water environment had attracted more attention. (2) The frequent occurrence of cave environment related keywords, such as "cave", "sinkhole", "speleothem", and "speleogenesis" implicated that cave environment study was an important research focus. (3) Those keywords such as "hydrochemistry", "geochemistry", "geomorphology", and "hydrogeology", suggested the branches of vulnerable karst environment study. (4) The nation identity related keywords such as "China", "Italy", and "Spain" suggested the increasing influence of these countries in the field of vulnerable karst environment research. In addition, the stable isotope method, technology of geographic information system (GIS), conservation of karst ecosystem, and climate change are also important issues. Karst hydrology and cave environment study received stable and continued attention; stable isotope and GIS technologies rapidly progressed, yet they still account for a small proportion in the research field. The results of our study revealed the inevitable trend of conducting comprehensive studies, which 3-dimentionally combine the above and underground elements, for the purpose of securing ecological safety.

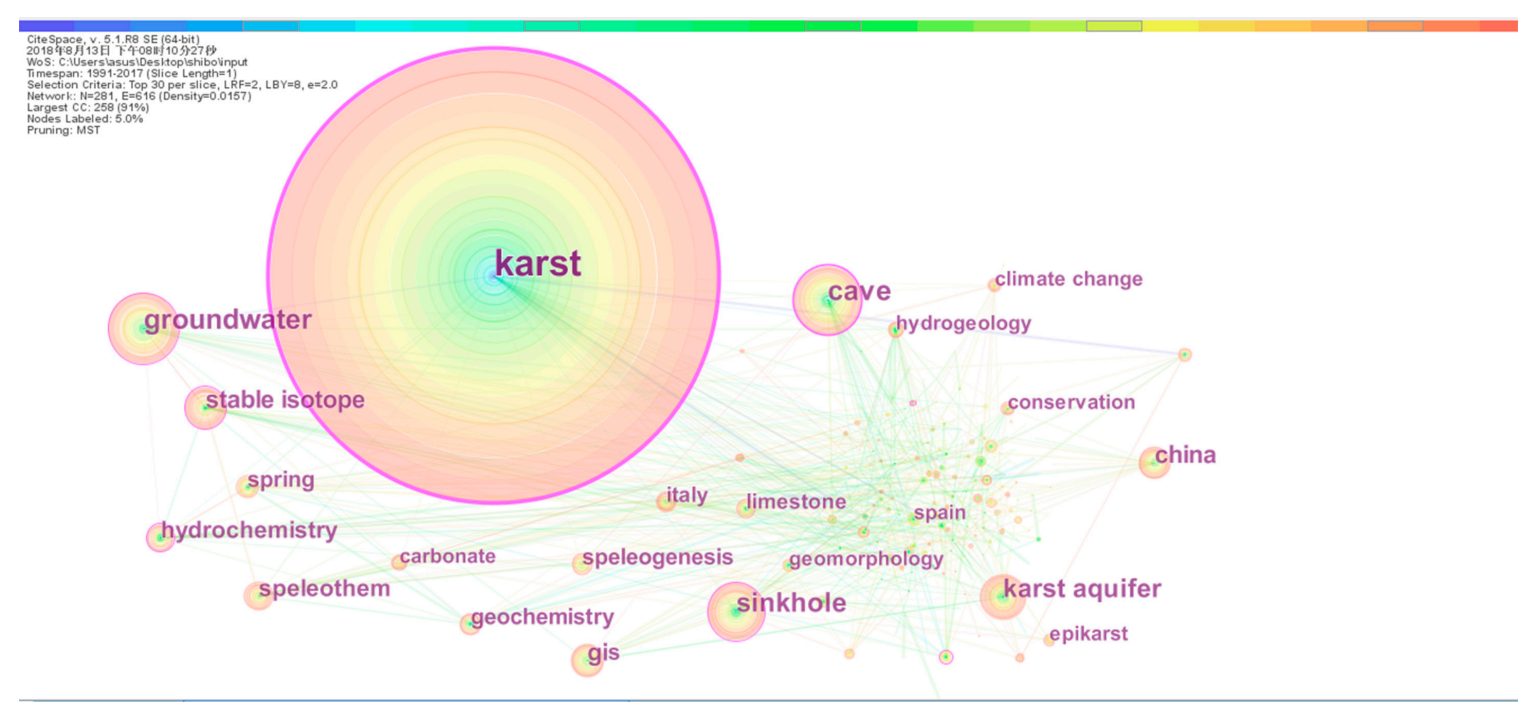

Figure 4. The co-occurrence relation of keywords about "vulnerable karst environment" in SCI/SSCI journal articles published from 1991 to 2017.

By investigating the burst terms in vulnerable karst environment researches (Figure 5), the keyword "karst" was found at the top of the list with intensity of 7.761. Its impact duration was from 1991 to 1996. Keyword "hydrology" with intensity of 4.3264 ranked the second and its impact duration was from 1994 to 2008. Keyword "biogeography" with its intensity of 3.4869 and impact duration from 1994 to 2009 took the third position. Then there was a surging of keywords including "Slovenia" (intensity: 5.9329; impact duration: 2002-2009), "karst hydrology" (8.6885; 2003-2009), and "speleogenesis" (6.3853; 2009-2011). The burst terms appeared recently included "carbon isotope" (5.7482; 2010-2012), "new specy" (4.8023; 2010-2014), “Croatia" (4.4348; 2010-2014), "Dinaric karst" (4.348; 2010-2012), "karst groundwater" (4.1339; 2010-2013), and "modeling" (3.4386; 2010-2014). Those keywords have clearly depicted the flowchart of vulnerable karst environment research progress, which is from process and mechanism research to application and modeling research. 


\section{Top 25 Keywords with the Strongest Citation Bursts}

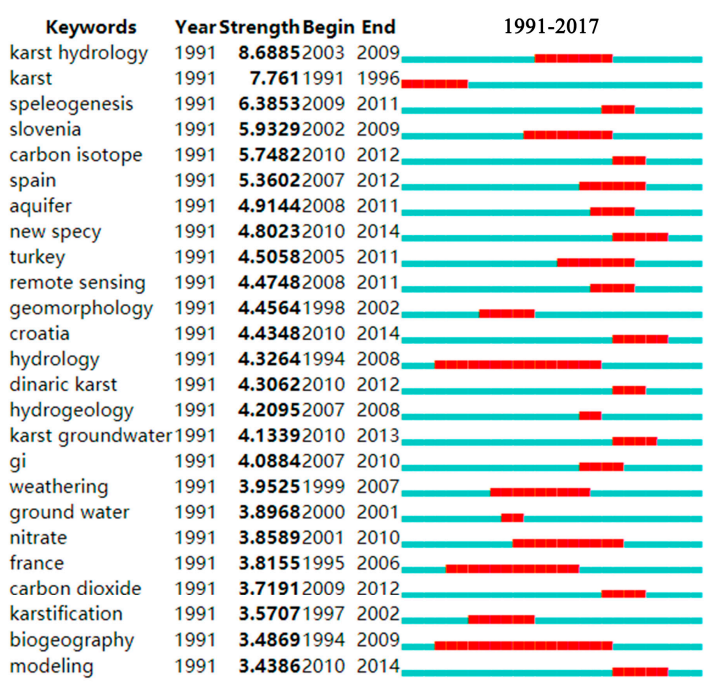

Figure 5. Top 25 Keywords with the strongest citation bursts.

Figure 6 shows the clustering graph of keywords about "vulnerable karst environment" appeared in SCI/SSCI journal articles from 1991 to 2017, from which several clusters formed in the past 27 years in the field can be detected. (1) The karst water environment related keywords, such as "karst", "groundwater", "hydrology", "contamination", and their interrelation indicated that karst water environment had drawn more attention. (2) The fact that keywords "speleothem", "organic matter", "stable isotope", and "carbonate" were clustered implicated that it was common to study the changes in karst ecosystem based on sediments in the karst region. (3) Keywords "vegetation", "ecosystem", "biodiversity", "flow" and "land use", "precipitation", "climate change" were grouped respectively, which suggested that ecosystem study and climate and land use research were both major directions of vulnerable karst environment researches. (4) The interrelation of keywords "aquifer", "soil", "pattern", "cave", and "geochemistry" showed that the importance of geochemistry method in soil, cave, and aquifer researches was increasingly emphasized. Furthermore, model simulation, GIS, evolution and development, rivers, and basins were also important issues. The keywords clustering showed that the research subjects in the field of vulnerable karst environment were scattered. There was no matured research system or subject discipline but there was obvious intersection of other disciplines.

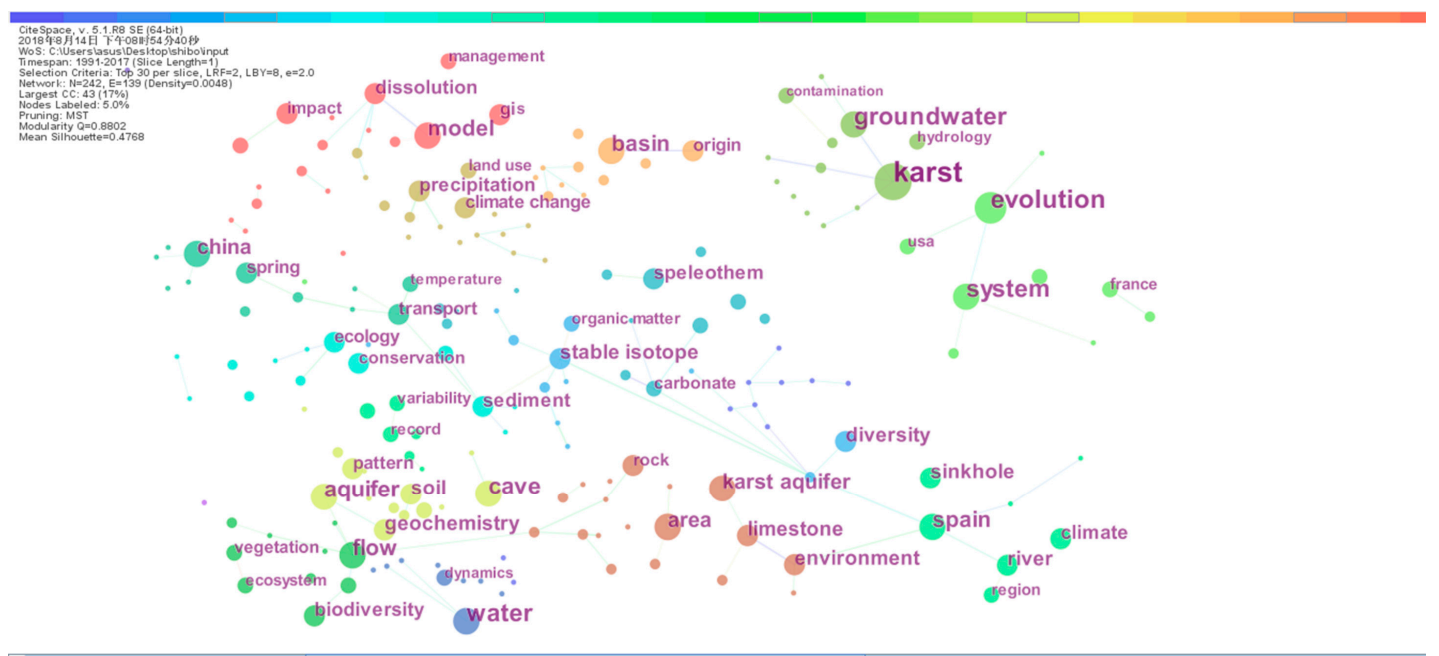

Figure 6. The clustering analysis of keywords about "vulnerable karst environment" in SCI/SSCI journal articles from 1991 to 2017. 


\subsection{Author Influence}

Figure 7 shows the network or authors in the field of "vulnerable karst environment" in SCI/SSCI journal articles. It was clear that some dominant authors, such as Wang Kelin, Yuan Daoxian, Gutierrez Francisco, and Zhang Wei played leading roles in the field. The scattered distribution of authors indicated that there was little cooperation of authors, which suggested that a complete and close cooperation network had not yet established. Quinif Yves, Calaforra Jose-Maria, Pulido-Bosch Antonio, Jeannin Pierre-Yves, Bakalowicz Michel, and Plagnes Valerie started their studies earlier, but they published less and continued their research only for a short duration. Yuan Daoxian, Wang Shijie, Liu Congqiang, Gabrovsek Franci, Liu Zaihua, Andreo Bartolome, Parise Mario, and Gutierrez Francisc started their researches earlier with higher publication frequency and longer duration. Although Wang Kelin, Chen Hongsong, Zhang Wei, and De Waele Jo started their researches late, they published more frequently and represented the state-of-the-art in the field. In general, authors with their research interests in the field of vulnerable karst environment should strengthen their cooperation and improve the continuity and depth of research.

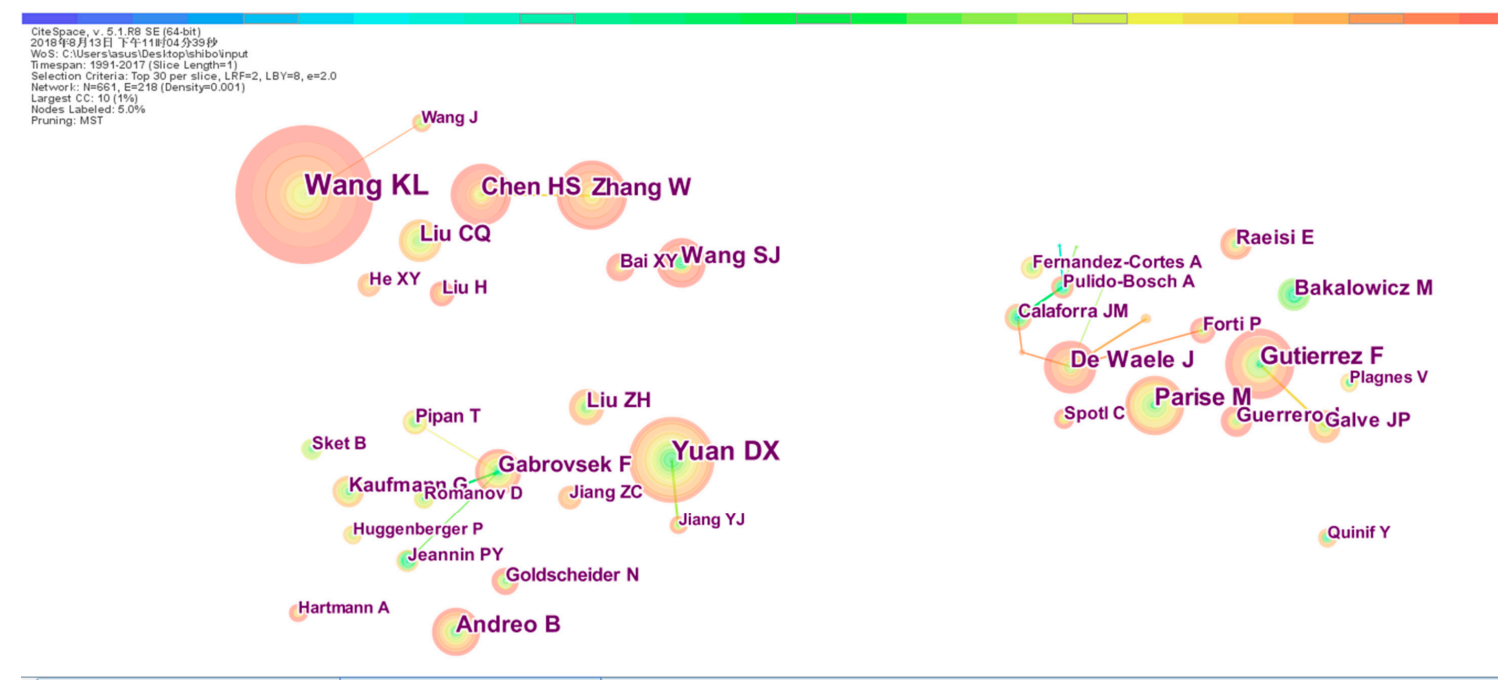

Figure 7. The major author network of SCI/SSCI journals about "vulnerable karst environment".

By analyzing the top 18 authors in the strongest outbreak of citations between 1991 and 2017 (Figure 8), it was found that the explosive growth began in 1999. Author "Wang Kelin" launched his citation outbreak (12.3778) in 2015-2017, which highlighted his significant influence on recent researches. "Bakalowicz Michel" (7.7154; 2001-2008) and "Zhang Wei" (6.1948; 2014-2017) ranked the second and the third, respectively. These three authors were the leading players in the field. Calaforra Jose-Maria (3.882; 1999-2008), Jeannin Pierre-Yves (4.386; 1999-2007), Bakalowicz Michel (7.7154; 2001-2008), and Sket B (3.3786; 2004-2010) had the longest author influence duration, which indicated their persistence in the field. Those authors with the strongest citation outbreaks, such as "Wang Kelin", "Zhang Wei", and "Chen Hongsong", represent the newly emerged force that are currently in a leading position. Authors from China secured 9 positions, accounting for $50 \%$, in the list of the top 18 authors, which demonstrated the prominence of China in this field.

Through the clustering analysis of research teams in the field of vulnerable karst environment (Figure 9), it was found that the points of focus of authors were very different. There was no established good cooperation system. Authors in the field of karst ecosystem research can be categorized as follows: Chinese authors, whose research interests were about the restoration and rehabilitation of the ecosystem in south China, formed a network which was led by Wang Kelin, Wang Shijie, Liu Congqiang, and Chen Hongsong. Their research topics included: patterns and models of ecosystem in karst region, the damage mechanism and rehabilitation of karst degradation ecosystem, karst rocky desertification 
control, and the geochemical process and eco-environmental effect. Chinese author Yuan Daoxian, Liu Zaihua, Slovenian author Gabrovsek Franci, and Spanish Author Andreo Bartolome formed a network with their interests in the areas of karst ecosystem, hydrological environment, the vulnerability of landscape, and the evolution of aquifer. Other authors, represented by Italian authors De Waele Jo and Parise Mario, Spanish author Gutierrez Francisco, and French author Bakalowicz Michel, focused their attention on surface karst system and water resource protection and impact and assessment of karst environment. Their research topics included: the evolution of environmental impact in karst region, karst water resource protection, evaluation of the vulnerability of karst resource, human impact on karst ecosystem and its evaluation, the influence of hydrogeology and karst characteristics on karst environment, and restoration and reconstruction of karst paleo-ecosystem.

Top 18 Authors with the Strongest Citation Bursts

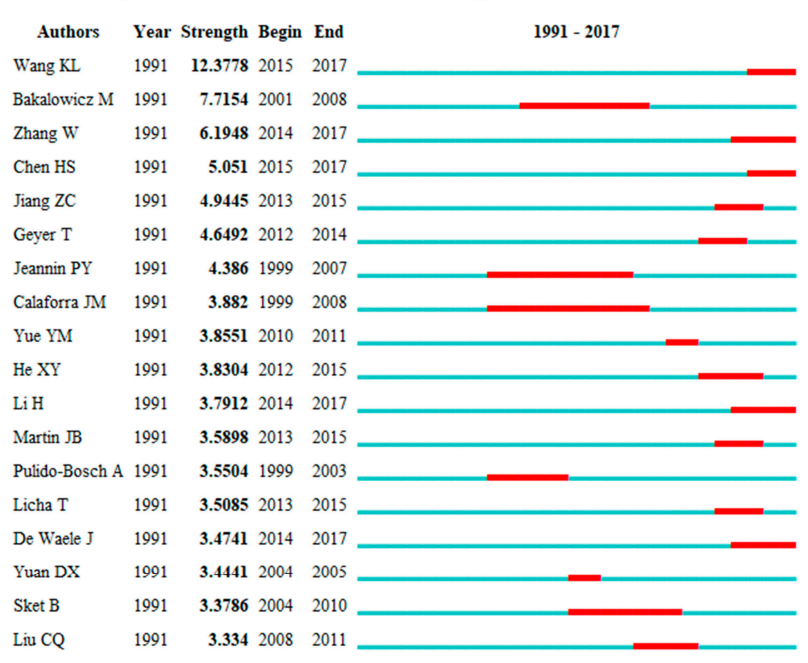

Figure 8. Top 18 Authors with the Strongest Citation Bursts.

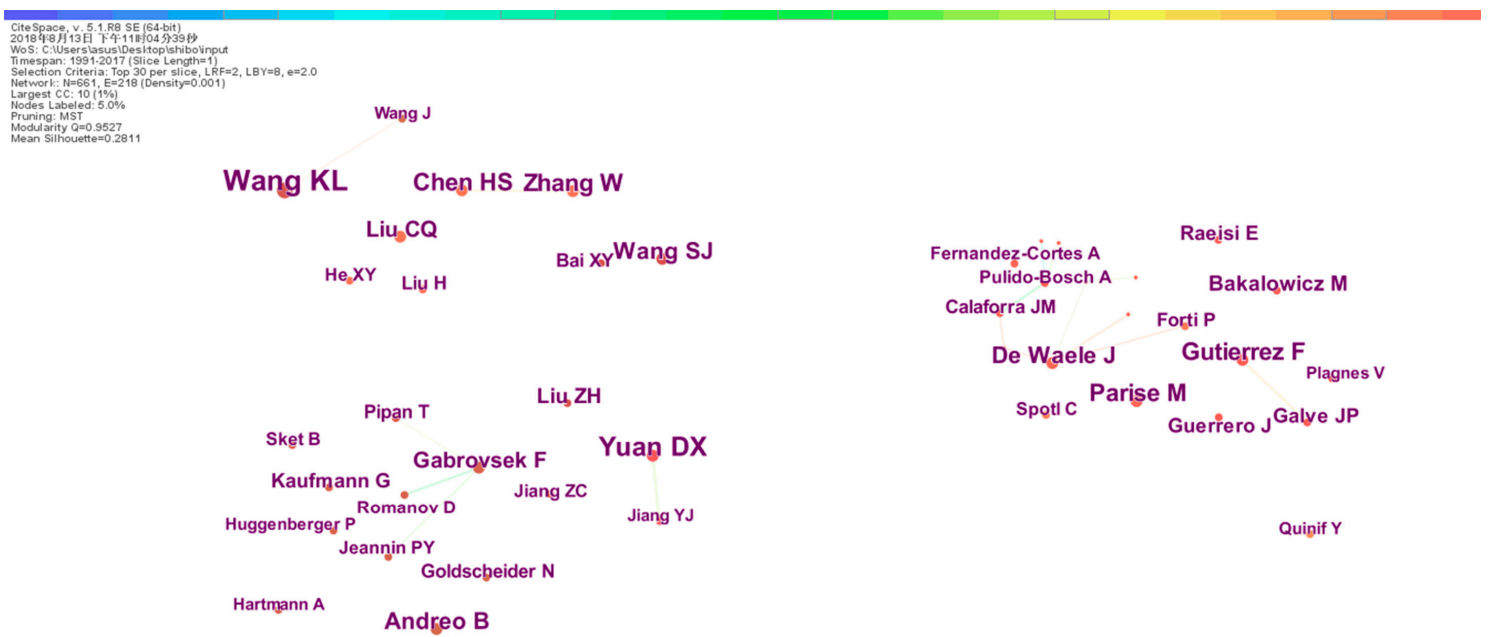

Figure 9. The clustering analysis on major authors of SCI/SSCI journal articles about "vulnerable karst environment" from 1991 to 2017.

\subsection{Analysis of Research Hotspots}

In the past 20 years, vulnerable karst environment has received increasing attention and scientific input, setting off the outbreak of academic achievements in the field. The foam tree visualization picture (Figure 10), which was acquired by analyzing the top 100 searching results from WOS in Carrot2 
software, provided us the keywords and subtopics in the field, which established the foundation for more comprehensive and objective analysis on the recent research situation and hotspots in the field.

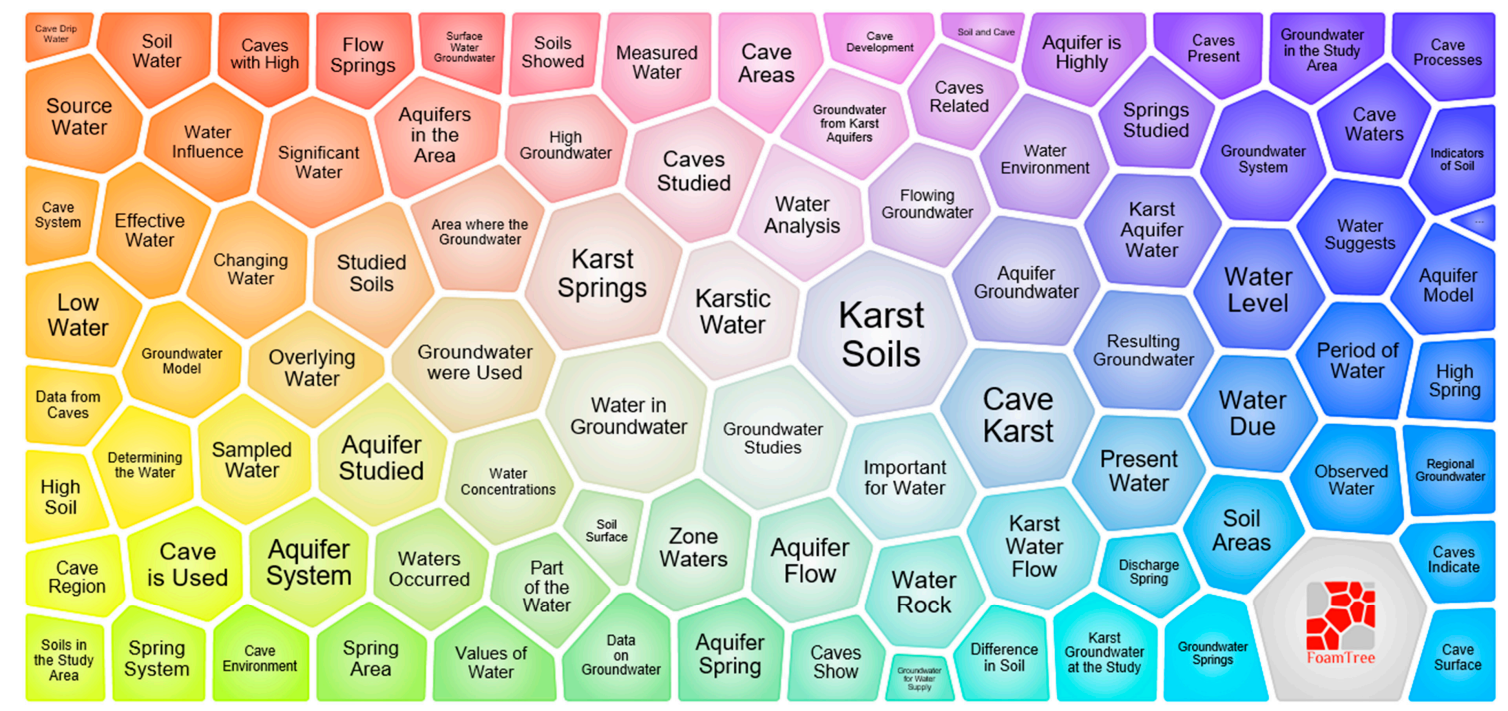

Figure 10. Foam tree visualization of search results on eco-environment vulnerability in karst region with Carrot based on Web of Science search results.

Figure 10 described the major topics in the field of vulnerable karst environment, indicating that karst soils, cave karst, water in groundwater, karst springs, groundwater studies, and groundwater were used were the research hotspots in the field. With the advantages of being more stringent, more reliable, more detailed, and more specific, the WOS database-based clustering analysis was applied to karst water environment, karst cave environment, and karst soil environment studies. (1) Karst water environment, which is tightly connected with karst ecological environment, is one of the hottest topics in the field. This topic covered studies about both groundwater and surface water. The influence and importance of water, water function, aquifer system, spring system, changes of water, and the utilization of water were the research focuses in the field. (2) Over the past decades, karst cave environment researches have attracted more attention since they provided important references for the study of a karst ecosystem. Karst cave studies focused on the development of cave system, utilization and protection of cave system, the soil-cave connection and water-cave connection, and indicators of cave sediments on ecological evolution. For example, stalagmite, as a kind of cave sediment whose growing process is closely related to environment changes, is an important information source of environment evolution. (3) In terrestrial ecosystems, the soil system is the most active one, which provided human beings with the critical resources and ecological environment conditions to survive. Karst soil environment, the foundation of karst ecological environment, was also a hot topic in the filed in spite of its infrequent appearance. The indicators, such as soil water, soil erosion, and soil characteristics were the research focuses. In karst regions in south China, the soil environment was undermined due to its vulnerability and the irrational interference of human beings, which caused a decline in land productivity and desertification problems. Karst water environment, cave environment, and soil environment, independent and interrelated, formed the research hotspots in the field of karst ecosystem researches. 


\subsection{Cited Reference Co-Citation Network Analysis}

Figure 11 shows the co-citation relationship of publications with high citation frequencies in the field of vulnerable karst environment studies. Ford D.'s book "Karst hydrogeology and geomorphology" [65] impacted the research filed the most with a milestone citation frequency of 318 times. This work introduced karst erosion kinetics, chemical equilibrium, and laws of physical flow in the first part. In the second part, the influence of cave system and climate on karst regions was discussed and some important environment management issues, such as karst environment assessment, environment restoration, influence of tourism, and value of protection were addressed. Bakalowicz M.'s [66] article "Karst groundwater: a challenge for new resources" ranked the second with a citation frequency of 66 times. It mainly discussed the development and protection of an aquifer in terms of its structure, function, and vulnerability. The third article, Gutierrez F.'s "A review on natural and human-induced geohazards and impacts in karst" [11], was cited 62 times and mainly reviewed the major characteristics of natural and human-induced geohazards and summarized the research progress in the field. As can be seen from top 30 high-cited papers, they mainly focused on karst water environment (aquifer), karst rocky desertification, cave environment, paleoenvironment reconstruction, and the formation mechanism of karst sinkhole. Among them, papers on karst water environment (aquifer) accounted for the highest proportion. Research topics about karst water environment included using hydrological models to study karst water resources, karst groundwater vulnerability assessment, karst eco-hydrological framework, slope runoff and aquifer evolution, etc. Furthermore, there were many highly cited papers on the mechanism of karst rocky desertification, driving mechanism and ecological restoration and reconstruction. Studies about karst fissures, carbon sinks, soil erosion, etc., have also attracted attention.

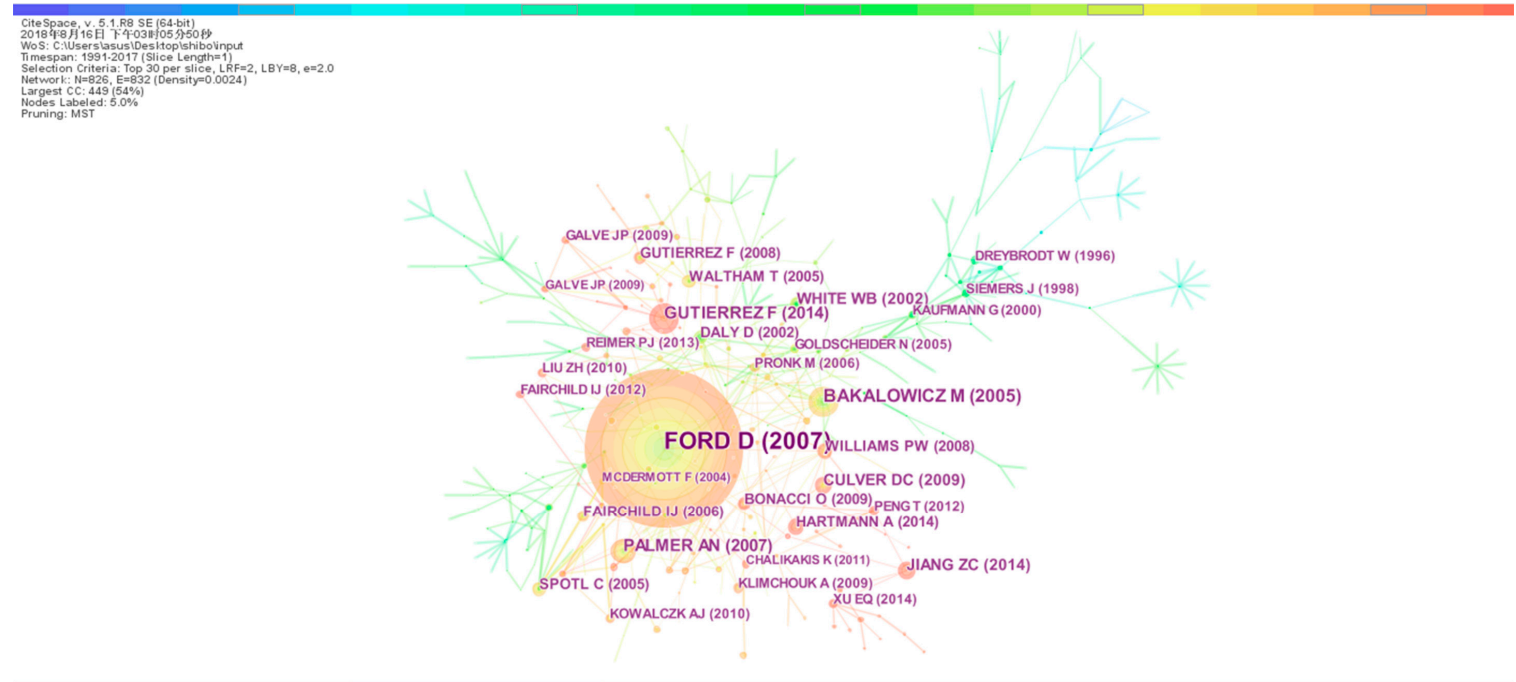

Figure 11. The co-citation network of highly cited publications in the field of vulnerable karst environment.

Figure 12 shows the top 25 citations with the strongest burst values between 1991 and 2017. The earliest and strongest burst went to Ford D.'s book "Karst Geomorphology and Hydrology" [67]. It was started in 1991 and ended in 1997 with a strength value of 16.4623, which indicated its significant influence in the field. This book discussed environmental factors that affected karst environmental chemical evolution, classification of cave system, the influence of climate on karst development, and management of karst water resources. White WB.'s paper entitled "Karst hydrology: recent developments and open questions" [68] ranked the second on the list of citation burst with strength value of 12.2087. Its citation burst duration was from 2004 to 2010. In this paper, the author summarized the research progress of water resources development and utilization, tracer research, hydrological 
analysis and chemical analysis, and proposed a complete aquifer model and a transportation model of sediments in aquifers, which contributed to the process and mechanism study of sediments transportation in aquifers. Dreybrodt W.'s [69] paper, highly cited between 1999 and 2004 with strength value of 11.5223 revealed the law of early development of karst conduits under natural and man-made conditions via using a numeric model. The two papers authored by Kaufmann G. [70] and Fairchild I.J. [71] had the longest citation burst duration. They both started in 2001 and ended in 2008. The former studied the evolution of karst aquifers under different conditions, while the latter studied the influence of the control of trace elements in carbonate cave water on the cave climate record. The fact that there was no highly cited paper published in the field since 2011 had sent out a call of reinforcement in the area.

\section{Top 25 References with the Strongest Citation Bursts}

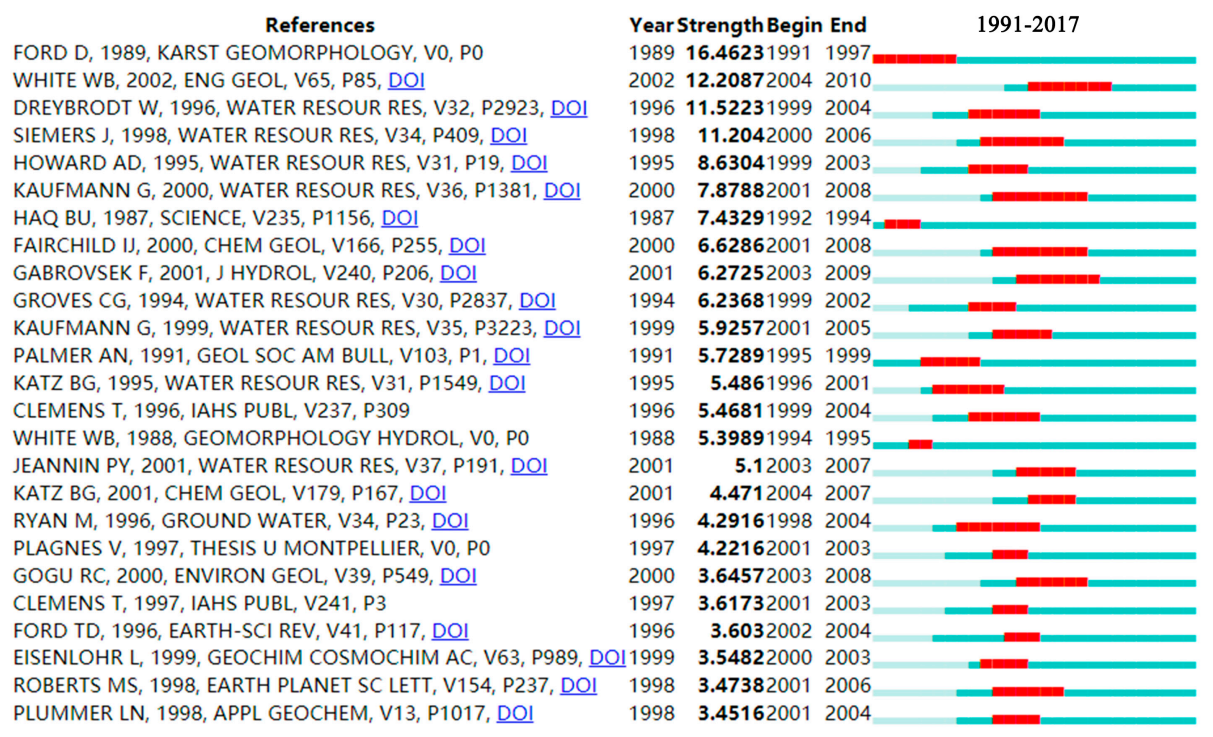

Figure 12. Top 25 References with the strongest citation bursts.

\subsection{Geographical Visualization Analysis of Research Institutions}

Based on the addresses mentioned in scientific papers, the geographic distribution of vulnerable karst environment research institutions was mapped by using CartoDB platform. As shown in Figure 13, the top papers in this field were mainly distributed in North America, European, and China, and a few in Brazil, South Africa, Australia, New Zealand, and Japan. The global distribution of carbonate rocks is generally around the carbonate belt. There are three major karst areas, namely, the East Asia karst area, the surrounding European Mediterranean karst area and the eastern United States karst area. Specific regions include southwest China, northern Vietnam, the Alps area of Central and South Europe, the Central Plateau of France, the Ural region of Russia, Eastern North America and Cuba and Jamaica of Central America. These areas are the major ecologically vulnerable areas in the world [72]. The distribution of research institutions in the field basically coincided with the global distribution pattern of karst. It also shows that the study of vulnerable karst environment has attracted research institutes from all over the world. 


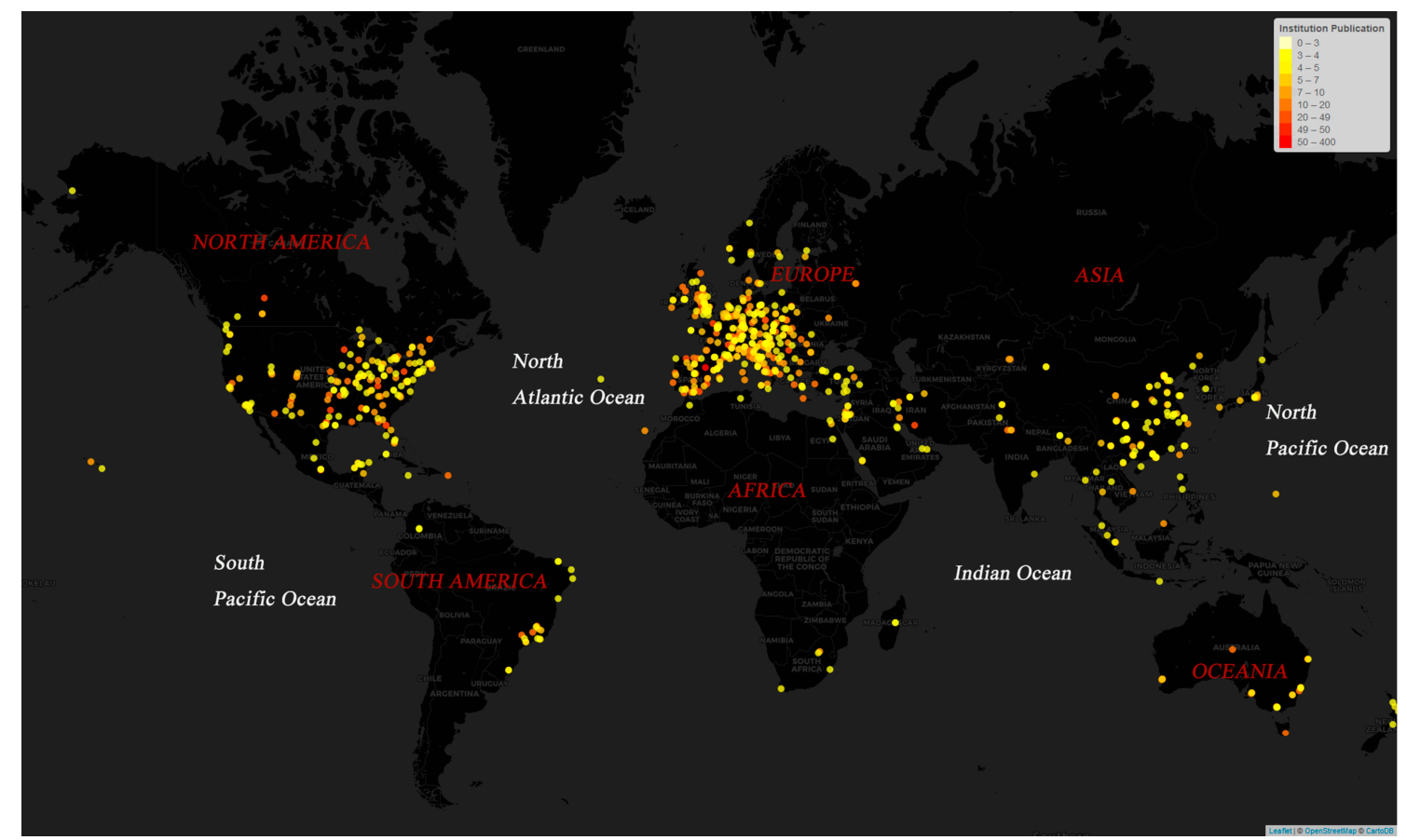

Figure 13. The distribution of global research institutions on vulnerable karst environment.

\subsection{National/Regional Contribution Analysis}

The national/regional cooperation network on vulnerable karst environment research was analyzed by using VOSviewer software (Figure 14). At least 2 papers were published in the country or region that appeared in the network. The cooperative clusters are differentiated by colors. There are 12 clusters formed in the figure. The first group include Greece, Macedonia, Brazil, Albania; the second group include Belgium, Mexico, Thailand, and Russia. The third group is around Canada, including China, Sweden, and Switzerland. The fourth group include Norway, Ireland, England and North-Ireland; the fifth group is led by France, followed by Laos, Turkey, Romania and Algeria; the sixth group include Slovakia and Croatia; the seventh group is led by Montenegro, and other cooperating countries include Bosnia and Herzegovina and Serbia; the eighth group includes Singapore and Malaya; the ninth group includes countries/regions such as Germany, Austria, Vietnam and Scotland; the Netherlands is the representative in Group 10, cooperating with Cuba and Italy; Iran and Lebanon form Group 11; Australia takes the lead in Group 12, followed by Indonesia and Taiwan. The research shows that there was certain geographic connections among the countries and regions in the cooperation network, and the publications mainly came from the most productive countries.

\subsection{Future Research}

\subsubsection{Evolution of Research Topics}

In order to understand the evolution process of research topics on vulnerable karst environment, the timeline of year by year clustering was depicted in Figure 15. Researches in the field were mainly concentrated on 10 large clusters. Longitudinally, the two largest clusters \#0 karst aquifer evolution and \#1 karst spring were important topics, although similar, in the field of vulnerable karst environment. They both paid close attention to karst water environment. Cluster \#0 focused on the evolution process of karst aquifer, while \#1 focused on the hydrological process of karst spring. Cluster \#2 addressed the formation and evolution process of cave. Cluster \#3 emphasized the evolution of karst ecological environment, from the study of factors affecting karst ecosystem to vegetation, land use, and karst rocky desertification. Cluster \#4 studied quaternary palaeohydrological evolution by using isotope technique on sediments. Cluster \#5 studied eastern desert, from the formation of carbonate rocks to 
palaeogeography to watershed, which showed the development process of karst researches. There were great changes of topics in clusters \#6 (karst massif), \#7 (Suwannee river basin), \#8 (glacial-proglacial system), and \#9 (Yucatan peninsula), which indicated the instabilities due to a lack of long-term research focuses and changes of research directions. Horizontally, we can see that researches in the fields of \#0, \#1, \#2 and \#5 were started earlier and lasted longer; \#3 lasted the longest from 1991 to 2017, indicating that this research topic received continued attention of researchers. Studies of \#6, \#7, \#8, and \#9 started late and lasted for a short time. The results of our study showed that researchers have kept their focus on the keywords changes of these research topics in their respective time periods.

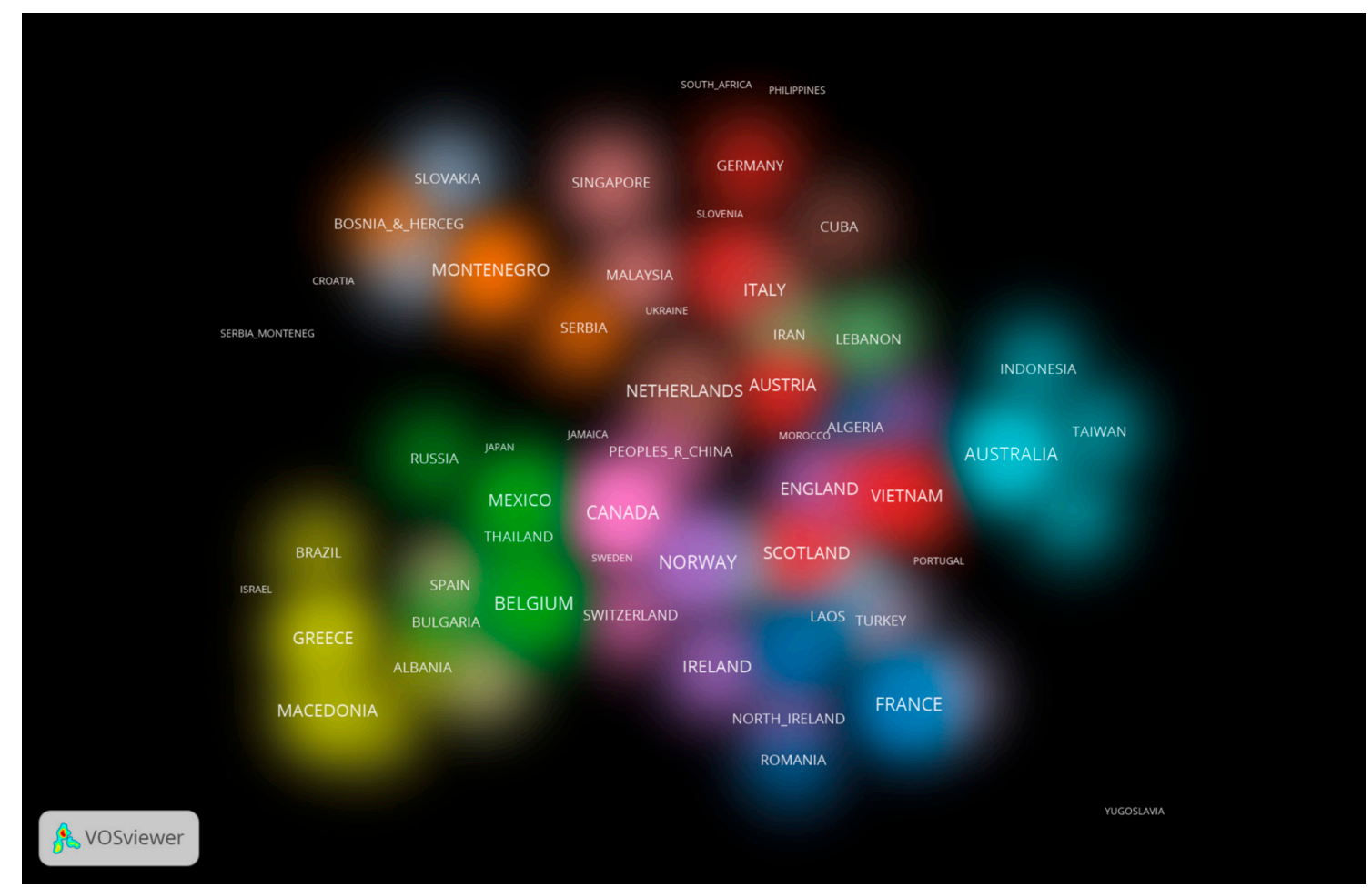

Figure 14. The national/regional cooperation network of vulnerable karst environment research.

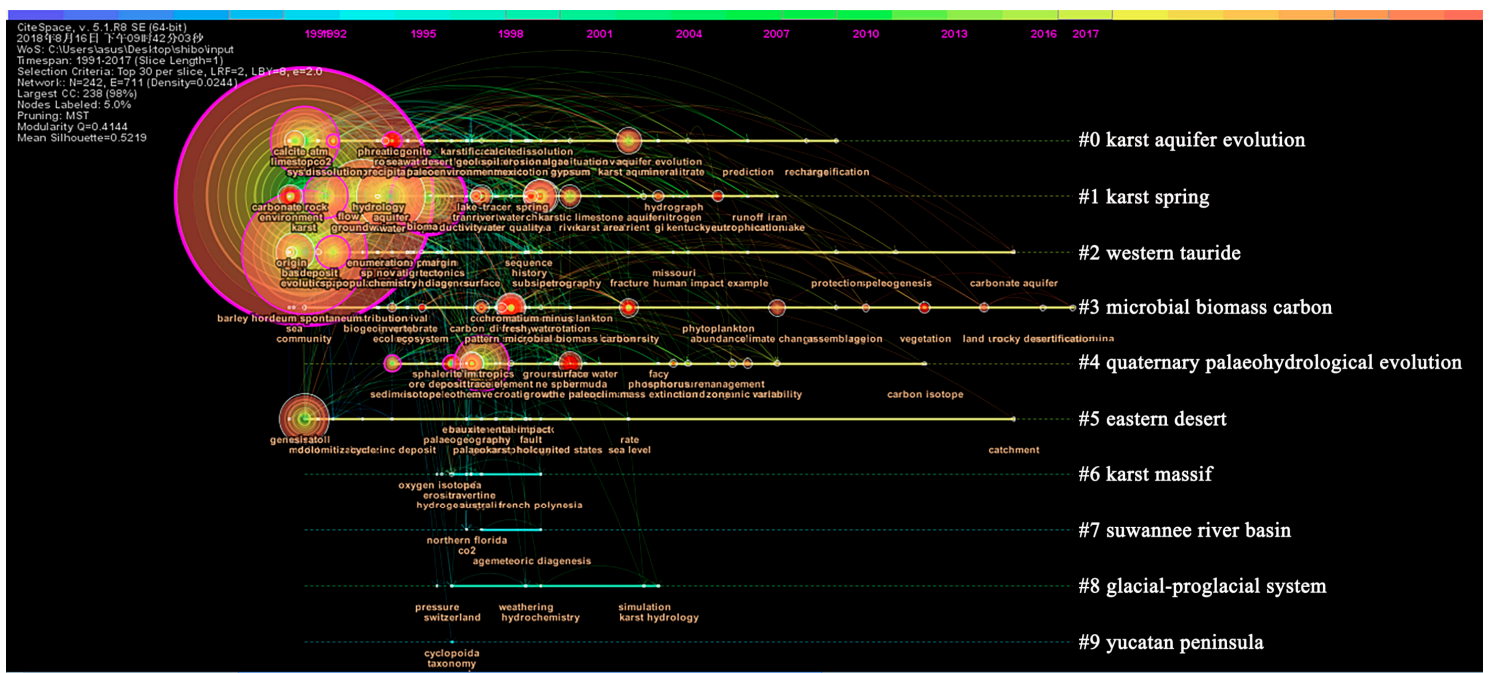

Figure 15. Timeline view of research topics year by year.

Keywords burst rate is an indicator of researcher's interests, the stronger the burst the more attention on the research topic. It implicated the cutting edge studies in the field in a specific period of 
time (Figure 16). "France" was the strongest keyword on the list with strength of 10.2681 and impact duration from 1995 to 2006, which indicated that vulnerable karst environment research was hot in France. Keywords "carbonate (8.9977)", "dolomitization (8.344)", "karstification (7.3275)", "calcite (7.3046)", "diagenesis (7.1718)", "dolomite (4.7682)", "sea (4.5896)", and "genesis (3.6623)" suggested that researches on karst environment foundation and its formation process were also hot. The burst of keywords "sediment (7.3551)", "isotope (6.2158)", "oxygen (5.1642)", and "deposit (5.0845)" indicated that sediments studies in karst regions by using isotope/oxygen isotope techniques were research focuses as well. The emergence of keywords "kinetics (6.7993)", "stratigraphy (6.1077)", "tectonics (4.4546)", "biogeography (3.9233)", and "hydrogeology (3.6836)" demonstrated the typical characteristics of interdisciplinary and integration of karst environmental research. Furthermore, keyword "stream (6.9168)" could be related to karst hydrological environment research. Keyword "population (5.0897)" could be considered as a research focus on karst ecosystem/biodiversity studies. Keyword "Australia (4.5299)" indicated the significant influence of Australia in the field of karst environment research. Keyword "erosion (3.8971)" implicated the research focus on the causal relationship between soil erosion and vulnerability of karst environment. "Carbonate platform (3.6622)" is an implicit term in this field, which implied that the vulnerable karst environment might have developed from carbonate platform. The emergence of "travertine (3.3963)" and "tufa (3.3963)" showed that the travertine landscape has also attracted the attention of academia.

\section{Top 25 Keywords with the Strongest Citation Bursts}

\begin{tabular}{|c|c|c|c|}
\hline Keywords & Years & Strength Begin End & 1991-2017 \\
\hline calcite & 1991 & 7.304619912005 & \\
\hline genesis & 1991 & 3.622319911999 & \\
\hline oxygen & 1991 & 5.164219912001 & \\
\hline dolomite & 1991 & 4.768219912003 & \\
\hline sea & 1991 & 4.589619912001 & \\
\hline carbonate & 1991 & 8.997719912004 & \\
\hline deposit & 1991 & 5.084519922000 & \\
\hline dolomitization & 1991 & 8.34419922000 & \\
\hline population & 1991 & $5.08971993 \quad 2002$ & \\
\hline sediment & 1991 & 7.355119942008 & \\
\hline stream & 1991 & 6.916819942005 & \\
\hline biogeography & 1991 & 3.923319941997 & \\
\hline france & 1991 & 10.268119952006 & \\
\hline carbonate platform & 1991 & 3.662219952000 & \\
\hline isotope & 1991 & 6.215819952008 & \\
\hline stratigraphy & 1991 & 6.107719952000 & \\
\hline erosion & 1991 & 3.897119962003 & \\
\hline hydrogeology & 1991 & 3.683619962002 & \\
\hline tectonics & 1991 & 4.454619962003 & \\
\hline diagenesis & 1991 & 7.171819962001 _. & \\
\hline travertine & 1991 & 3.396319972003 & \\
\hline australia & 1991 & 4.529919972003 & \\
\hline kinetics & 1991 & 6.799319972003 & \\
\hline tufa & 1991 & 3.396319972003 & \\
\hline karstification & 1991 & 7.327519972001 & \\
\hline
\end{tabular}

Figure 16. Keywords with the strongest citation bursts in research topics year by year.

The key words time zone map of vulnerable karst environment research (Figure 17) generally reflects the trend of research, from fundamental to frontier, in the time range of 1991-2017. The main keywords appearing in 1991-1995 were "karst", "evolution", "system", "basin", "limestone", "environment", "origin", "carbonate", "community", "Spain", "dissolution", "deposit", "groundwater", "flow", "water", "aquifer", "sediment", "precipitation", “ecology", "rock", "hydrology", "stream", "France", "ecosystem", "morphology", etc. The research focuses were on the carbonate geochemical reaction, surface and groundwater environment, ecosystem, etc. However, in 1995, the emergence of keywords "isotope", "stratigraphy", "carbonate platform", etc. marked the transformation of research in the field of vulnerable karst environment and signified the application of new research methods in this field. The keywords appearing in 1996-2000 were "speleothem", "diagenesis", "cave", "geochemistry", "sinkhole", "climate", "transport", "pattern", "contamination", "soil", "diversity", "conservation", “Croatia", "water quality", "area", "China", "spring", "dynamics", "subsidence", "river", "stable 
isotope", etc., which indicated that the subject area had been gradually expanded to cave environment, biodiversity, environment protection and pollution, regional research, application of isotopes, etc. Meanwhile, soil erosion, biodiversity and environmental evolution had also attracted attention. From 2001 to 2009, the emergence of keywords "paleoclimate", "karst aquifer", "biodiversity", "GIS", "USA", "karst hydrology", "record", "temperature", "impact", "organic matter", "management", "climate change", "variability", etc. indicated that the study of vulnerable karst environment tended to climate change, hydrological environment, soil environment, biodiversity, and the application of GIS technology. Keywords emerged from 2010 to 2017 including "region", "speleogenesis", "vegetation", "carbon isotope", "land use", "carbonate aquifer", "rocky desertification", "Southwest China", etc. This suggests that in recent years, the research hotspots of vulnerable karst environment migrated towards ecological reconstruction and restoration, land use, karst rocky desertification, and studies of southwestern China. Through the analysis of the evolution of the research topics, it can be found that since 1991, the research topics of vulnerable karst environment have been gradually refined and transferred from water environment research to cave environment, and ecological environment research, and then gradually reached the fields of ecological restoration and reconstruction and karst rocky desertification.

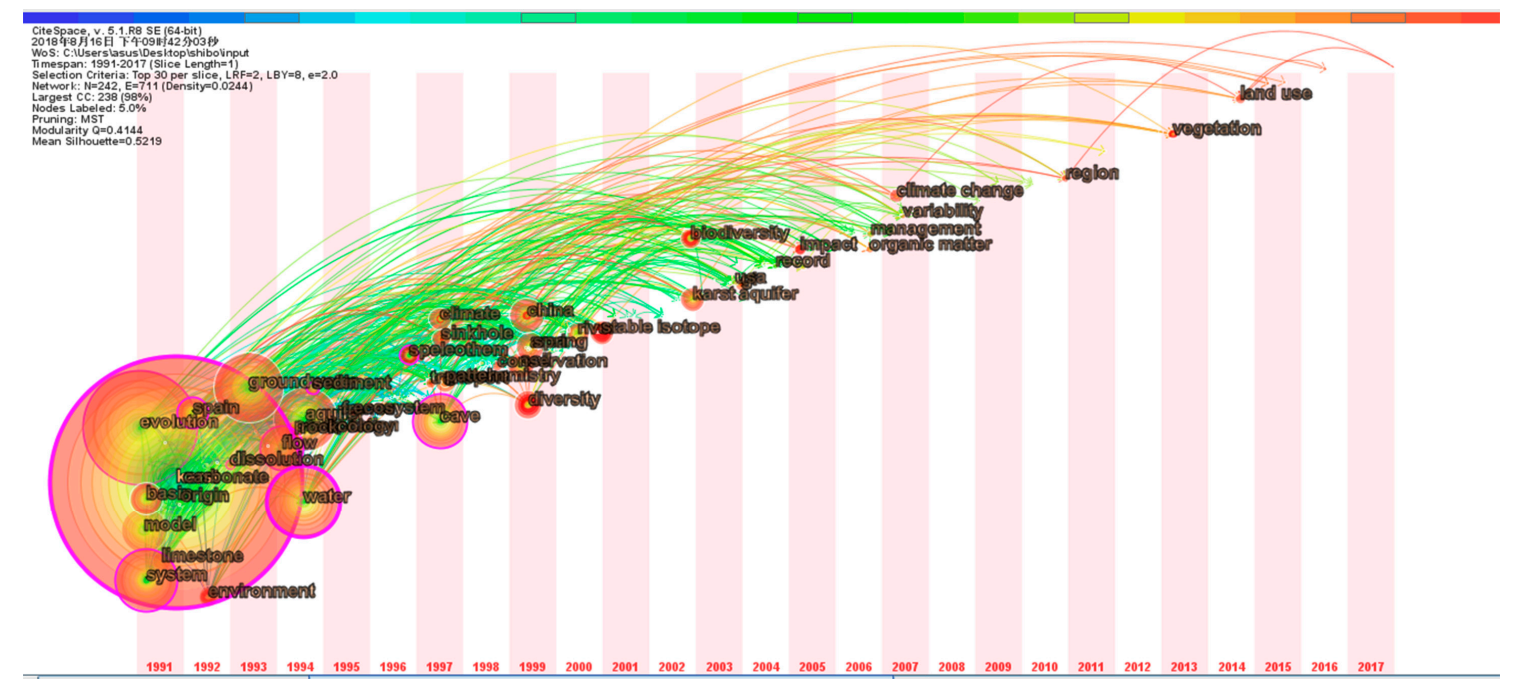

Figure 17. Keywords time zone map of vulnerable karst environment research.

\subsubsection{Major Cooperation Network}

By using Google Fusion Tables, the global vulnerable karst environment research hotspots were mapped based on the addresses provided in scientific articles (Figure 18). In Figure 18, green points represent active areas and red points represent highly active areas of research in the field. It can be seen that the study of vulnerable karst environment is widely distributed in the main karst regions, especially in the United States, Europe, China, Australia, and New Zealand. Vulnerable karst environment research received increasing attention. The main reason for this might be that the irrational social and economic activities of human beings have caused serious degradation and rocky desertification, resulting in degradation of ecosystem service and potential hazards $[1,5,20]$. For example, the total area of karst regions in eight provinces (cities/districts) in Southwest China is about $519,700 \mathrm{~km}^{2}$, of which the karst rocky desertification area is up to $136,400 \mathrm{~km}^{2}$ [72]; the sharp contradiction between human and land in this area leads to the emergence of vulnerable environmental landscapes such as vegetation reduction, land degradation, surface soil erosion, underground soil leakage, soil leanness, rocky desertification, cave pollution and water pollution. The negative effects on the natural environment, human social and economic development have aroused widespread concern from academia and the Chinese government on the karst vulnerable environment. 


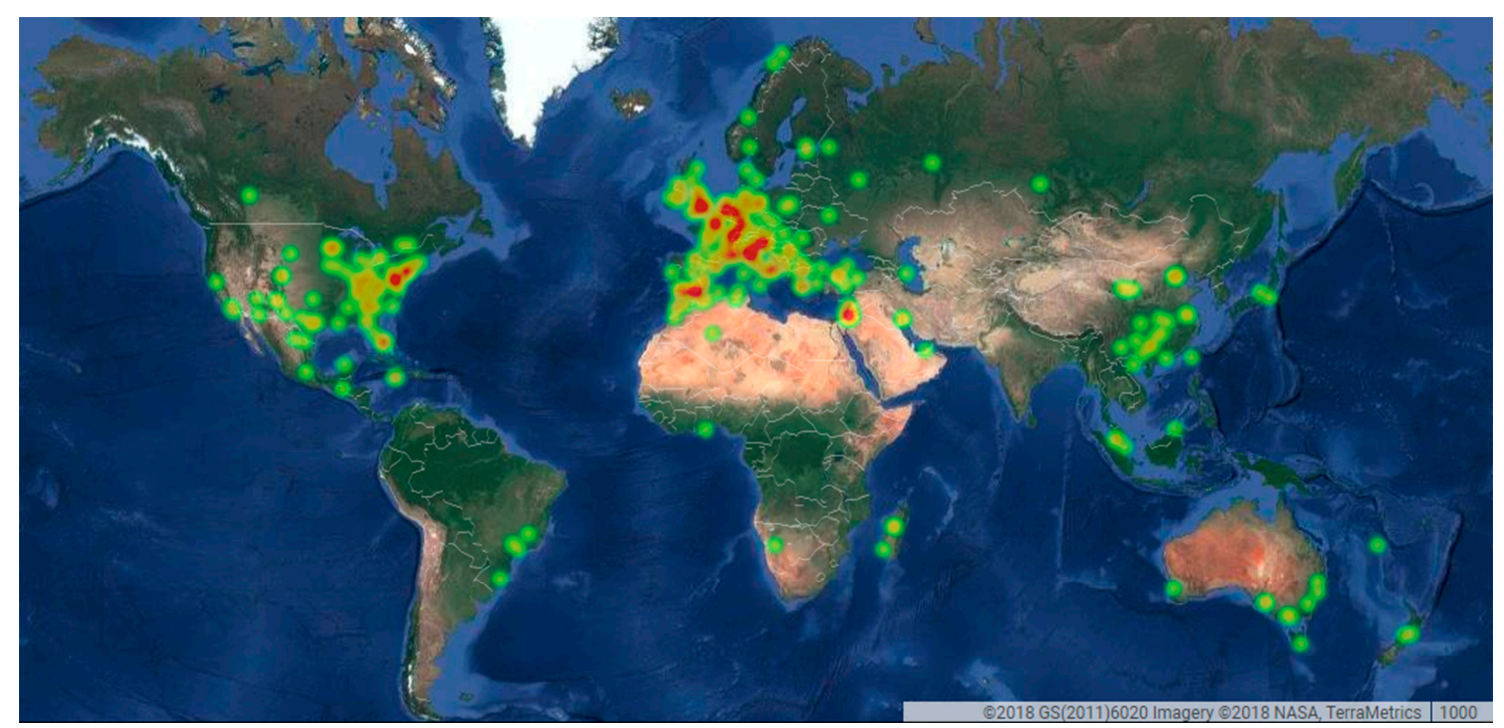

Figure 18. The hotspots of vulnerable karst environment research.

\section{Conclusions}

In this work, we undertook a systematic quantitative analysis of the literature in the field of vulnerable karst environment research. There were 5425 papers published in this field in 1991-2017, many of which were published after 2000. Although a few review papers about soil erosion and rocky desertification in karst regions have been published, there is still a lack of objective analysis based on comprehensive and systematical bibliometric methods. Our work helped identify research hotspots and papers and authors of significant impact, and pointed out the directions of researches in this field.

By analyzing a keywords network, we found that researches in the field of vulnerable karst environment have been built to scale. At present, the karst hydrological environment and cave environment research occupy a dominant position. Meanwhile, many new research perspectives and methods have attracted attention. Through the keywords clustering analysis, it can be seen that four groups of karst water environment: sediments, ecosystem, climate and land use, and geochemical methods have been formed. The four groups are relatively independent and closely connected. In general, researches in the field of vulnerable karst environment started from researches of hydrological environment and cave environment, and gradually transferred to the cross research of hydrochemistry, geochemistry and hydrogeology, and then to the application of new methods such as isotope, GIS, model simulation, etc. Researches on vulnerable karst environment have become more mature and formed a new interdisciplinary research area.

Through our analysis, it was found that a few significant authors, such as Wang Kelin, Yuan Daoxian, and Gutierrez Francisco, formed the core of research in the field of vulnerable karst environment. Author Wang Kelin, who had the strongest citation burst, together with other Chinese authors played a significant role in the field. From the clustering analysis of the research team, we see that, although there was no good cooperation network established, three research directions, including the restoration and reconstruction of karst ecological environment in South China; the research on karst ecosystem, change of water environment and landscape vulnerability; the research on surface karst ecosystem, water resource protection, and environmental impact and evaluation, clearly stood out as being the most fruitful academic achievements.

By analyzing the research hotspots in the field of vulnerable karst environment, water, cave, and soil environment research were identified as the hotspots. The most cited literature came from Ford D. (2007). The earliest and strongest citation burst value also belonged to the same author (Ford D., 1989). The regional distribution of achievements in the field of vulnerable karst environment showed that the output of papers was mainly from North America, Europe, and China, basically related to the spatial distribution of global karst regions. The 12 clusters in the national/regional cooperation network 
were connected and mutually influenced. Publications in the field of vulnerable karst environment researches mainly came from the most productive countries and regions. As an important emerging frontier research field, vulnerable karst environment research has specific topics and research focuses. It has evolved from fundamental to frontier research, from water environment to caver environment, ecological environment research, and gradually to ecological restoration and rehabilitation and karst rocky desertification research. With closer international cooperation, a cooperation network centered on Europe, the United States, and China has been formed.

Generally speaking, the research field of vulnerable karst environment is developing and maturing. Scholars have a late understanding of the vulnerability of karst regions. The appearances of landscapes in different vulnerable karst regions are different; the research focuses of scholars in different countries/regions are also different. Interdisciplinary research has a profound impact on this field. The application of fundamental knowledge and new methods is emphasized. The lack of international consensus has limited further study in this field. Yet, undoubtedly, research on the vulnerable karst environment is becoming an import part of global vulnerable ecological environment research. In order to provide a scientific basis for the sustainable development of karst regions, researchers should focus their attention on the formation mechanisms, degradation mechanisms, and restoration and rehabilitation of karst regions in future studies.

Author Contributions: Conceptualization, P.S., T.Z., and Z.L.; data curation, P.S., and T.Z.; formal analysis, P.S., and T.Z.; funding acquisition, Z.L.; investigation, P.S., T.Z., and X.F.; methodology, P.S., T.Z., and X.F.; Software, T.Z.; supervision, Z.L., and J.L.; validation, J.L.; writing—original draft, P.S., and T.Z.; writing—review and editing, P.S., and J.L. All authors have read and approved the final manuscript.

Funding: This research was funded by the National Natural Science Foundation of China (grant number 41761104), the Project of National Key Research and Development Program of China in the 13th Five-year Plan Period (grant number 2016YFC0502606), the Key Project of Science and Technology Program of Guizhou Province (grant number 54112017 Qiankehe Pingtai Rencai), 2017 Doctoral research project were launched by Guizhou Normal University, National Natural Science Foundation of China (grant number 41601584), Provincial Program on Science and Technology of Guizhou Province (grant number 71982016 Qiankehe LH), Guizhou Provincial Science and Technology Foundation (grant number Qiankehe Foundation [2017] 1417).

Acknowledgments: We thank Yi Jiang and Yin Zhang for their help in data processing.

Conflicts of Interest: The authors declare no conflict of interest.

\section{References}

1. Parise, M.; Pascali, V. Surface and subsurface environmental degradation in the karst of Apulia (southern Italy). Environ. Geol. 2003, 44, 247-256. [CrossRef]

2. Williams, P.W. Environmental change and human impact on karst terrains: An introduction. Catena 1993, 25, $1-19$.

3. Calò, F.; Parise, M. Evaluating the Human Disturbance to Karst Environments in Southern Italy. Acta Carsol. 2006, 35, 2-3. [CrossRef]

4. Yuan, D.X. Rock desertification in the subtropical karst of south China. Z. Geomorphol. 1997, 108, 81-90.

5. Jiang, Z.; Lian, Y.; Qin, X. Rocky desertification in Southwest China: Impacts, causes, and restoration. Earth Sci. Rev. 2014, 132, 1-12. [CrossRef]

6. Guan, D.; Su, W. Quantitative assessment of eco-environment vulnerability in karst region. Lowl. Technol. Int. 2014, 16, 45-53. [CrossRef]

7. Van Beynen, P.; Townsend, K. A disturbance index for karst environments. Environ. Manag. 2005, 36, 101-116. [CrossRef] [PubMed]

8. Su, Y.; Tang, Q.; Mo, F.; Xue, Y. Karst tiankengs as refugia for indigenous tree flora amidst a degraded landscape in southwestern China. Sci. Rep. 2017, 7, 4249. [CrossRef]

9. Zhao, L.; Hou, R. Human causes of soil loss in rural karst environments: A case study of Guizhou, China. Sci. Rep. 2019, 9, 3225. [CrossRef]

10. Tang, J.; Tang, X.; Qin, Y.; He, Q.; Yi, Y.; Ji, Z. Karst rocky desertification progress: Soil calcium as a possible driving force. Sci. Total Environ. 2019, 649, 1250-1259. [CrossRef] 
11. Gutiérrez, F.; Parise, M.; De Waele, J.; Jourde, H. A review on natural and human-induced geohazards and impacts in karst. Earth Sci. Rev. 2014, 138, 61-88. [CrossRef]

12. Martinotti, M.E.; Pisano, L.; Marchesini, I.; Rossi, M.; Peruccacci, S.; Brunetti, M.T.; Melillo, M.; Amoruso, G.; Loiacono, P.; Vennari, C.; et al. Landslides, floods and sinkholes in a karst environment: The 1-6 September 2014 Gargano event, southern Italy. Nat. Hazards Earth Syst. Sci. 2017, 17, 467-480. [CrossRef]

13. Parise, M.; Closson, D.; Gutiérrez, F.; Stevanović, Z. Anticipating and managing engineering problems in the complex karst environment. Environ. Earth Sci. 2015, 74, 7823-7835. [CrossRef]

14. Van Beynen, P.; Brinkmann, R.; Van Beynen, K. A sustainability index for karst environments. J. Cave Karst Stud. 2012, 74, 221-234. [CrossRef]

15. Xu, Z.; Massei, N.; Padilla, I.; Hartmann, A.; Hu, B. Characterization, modeling, and remediation of karst in a changing environment. Environ. Earth Sci. 2018, 77, 476. [CrossRef]

16. Stevanović, Z. Karst Environment and Phenomena. In Karst Aquifers-Characterization and Engineering; Stevanović, Z., Ed.; Springer: Cham, Germany, 2015; pp. 19-46.

17. Wang, L.-C.; Lee, D.-W.; Zuo, P.; Zhou, Y.-K.; Xu, Y.-P. Karst environment and eco-poverty in southwestern China: A case study of Guizhou Province. Chin. Geogr. Sci. 2004, 14, 21-27. [CrossRef]

18. Wang, S.J.; Li, R.L.; Sun, C.X.; Zhang, D.F.; Li, F.Q.; Zhou, D.Q.; Xiong, K.N.; Zhou, Z.F. How types of carbonate rock assemblages constrain the distribution of karst rocky desertified land in Guizhou Province, PR China: Phenomena and mechanisms. Land Degrad. Dev. 2004, 15, 123-131. [CrossRef]

19. Wang, S.J.; Liu, Q.M.; Zhang, D.F. Karst rocky desertification in southwestern China: Geomorphology, landuse, impact and rehabilitation. Land Degrad. Dev. 2004, 15, 115-121. [CrossRef]

20. Liao, C.; Yue, Y.; Wang, K.; Fensholt, R.; Tong, X.; Brandt, M. Ecological restoration enhances ecosystem health in the karst regions of southwest China. Ecol. Indic. 2018, 90, 416-425. [CrossRef]

21. Gewin, V. Ecosystem health: The state of the planet. Nature 2002, 417, 112-113. [CrossRef]

22. Zhang, M.; Wang, K.; Liu, H.; Zhang, C. Responses of spatial-temporal variation of Karst ecosystem service values to landscape pattern in northwest of Guangxi, China. Chin. Geogr. Sci. 2011, 21, 446-453. [CrossRef]

23. Yan, Y.; Dai, Q.; Wang, X.; Jin, L.; Mei, L. Response of shallow karst fissure soil quality to secondary succession in a degraded karst area of southwestern China. Geoderma 2019, 348, 76-85. [CrossRef]

24. Brinkmann, R.; Parise, M. Karst environments: Problems, management, human impacts, and sustainability an introduction to the special issue. J. Cave Karst Stud. 2012, 74, 135. [CrossRef]

25. Andriani, G.F.; Walsh, N. An example of the effects of anthropogenic changes on natural environment in the Apulian karst (southern Italy). Environ. Geol. 2009, 58, 313-325. [CrossRef]

26. Zhang, B.; Xiao, F.; Wu, H.; Mo, S.; Zhu, S.; Yu, L.; Xiong, K.; Lan, A. Combating the Fragile Karst Environment in Guizhou, China. Ambio 2006, 35, 94-96. [PubMed]

27. Bai, X.Y.; Wang, S.J.; Xiong, K.N. Assessing Spatial-Temporal Evolution Processes of Karst Rocky Desertification Land: Indications for Restoration Strategies. Land Degrad. Dev. 2013, 24, 47-56. [CrossRef]

28. Liu, M.; Zhang, Q.; Ge, S.; Mason, R.P.; Luo, Y.; He, Y.; Xie, H.; Sa, R.; Chen, L.; Wang, X. Rapid Increase in the Lateral Transport of Trace Elements Induced by Soil Erosion in Major Karst Regions in China. Environ. Sci. Technol. 2019, 53, 4206-4214. [CrossRef]

29. Zeng, C.; Wang, S.; Bai, X.; Li, Y.; Tian, Y.; Li, Y.; Wu, L.; Luo, G. Soil erosion evolution and spatial correlation analysis in a typical karst geomorphology using RUSLE with GIS. Solid Earth 2017, 8, 721-736. [CrossRef]

30. Kheir, R.; Abdallah, C.; Dalgaard, T.; Greve, M. Using visual erosion features to validate the application of water erosion models in Mediterranean karst environments: The case study of Lebanon. Z. Geomorphol. 2010, 54, 27-49. [CrossRef]

31. Zeng, F.; Jiang, Z.; Shen, L.; Chen, W.; Yang, Q.; Zhang, C. Assessment of multiple and interacting modes of soil loss in the karst critical zone, Southwest China (SWC). Geomorphology 2018, 322, 97-106. [CrossRef]

32. Barton, H.A.; Northup, D.E. Geomicrobiology in cave environments: Past, current and future perspectives. J. Cave Karst Stud. 2007, 69, 163-178.

33. Di Matteo, L.; Menegon, S.; Rossi, A.; Liti, S. Understanding karst environments by thermo-hygrometric monitoring: Preliminary results from the Cesi Mountain karst system (Central Italy). Acque Sotter. Ital. J. Groundw. 2016, 5, 25-32. [CrossRef] 
34. Rutlidge, H.; Baker, A.; Marjo, C.E.; Andersen, M.S.; Graham, P.W.; Cuthbert, M.O.; Rau, G.C.; Roshan, H.; Markowska, M.; Mariethoz, G.; et al. Dripwater organic matter and trace element geochemistry in a semi-arid karst environment: Implications for speleothem paleoclimatology. Geochim. Cosmochim. Acta 2014, 135, 217-230. [CrossRef]

35. Doerfliger, N.; Jeannin, P.Y.; Zwahlen, F. Water vulnerability assessment in karst environments: A new method of defining protection areas using a multi-attribute approach and GIS tools (EPIK method). Environ. Geol. 1999, 39, 165-176. [CrossRef]

36. Daly, D.; Dassargues, A.; Drew, D.; Dunne, S.; Goldscheider, N.; Neale, S.; Popescu, I.; Zwahlen, F. Main concepts of the European approach to karst-groundwater-vulnerability assessment and mapping. Hydrogeol. J. 2002, 10, 340-345. [CrossRef]

37. Liu, Z.; Li, Q.; Sun, H.; Wang, J. Seasonal, diurnal and storm-scale hydrochemical variations of typical epikarst springs in subtropical karst areas of SW China: Soil CO2 and dilution effects. J. Hydrol. 2007, 337, 207-223. [CrossRef]

38. Sheikhy Narany, T.; Bittner, D.; Disse, M.; Chiogna, G. Spatial and temporal variability in hydrochemistry of a small-scale dolomite karst environment. Environ. Earth Sci. 2019, 78, 273. [CrossRef]

39. Mijošek, T.; Filipović Marijić, V.; Dragun, Z.; Krasnići, N.; Ivanković, D.; Erk, M. Evaluation of multi-biomarker response in fish intestine as an initial indication of anthropogenic impact in the aquatic karst environment. Sci. Total Environ. 2019, 660, 1079-1090. [CrossRef]

40. Alili, L.; Boukdir, A.; Maslouhi, M.R.; Ikhmerdi, H. Karst groundwater vulnerability mapping to the pollution: Case of Dir springs located between EL KSIBA and Ouaoumana (High Atlas, Morocco). E3S Web Conf. 2018, 37, 01004. [CrossRef]

41. Adinehvand, R.; Raeisi, E.; Hartmann, A. A step-wise semi-distributed simulation approach to characterize a karst aquifer and to support dam construction in a data-scarce environment. J. Hydrol. 2017, 554, 470-481. [CrossRef]

42. Brookfield, A.E.; Macpherson, G.L.; Covington, M.D. Effects of Changing Meteoric Precipitation Patterns on Groundwater Temperature in Karst Environments. Groundwater 2017, 55, 227-236. [CrossRef] [PubMed]

43. Xu, D.; Wang, Y.; Zhang, R.; Guo, J.; Zhang, W.; Yu, K. Distribution, speciation, environmental risk, and source identification of heavy metals in surface sediments from the karst aquatic environment of the Lijiang River, Southwest China. Environ. Sci. Pollut. Res. 2016, 23, 9122-9133. [CrossRef] [PubMed]

44. Schmidt, S.; Geyer, T.; Marei, A.; Guttman, J.; Sauter, M. Quantification of long-term wastewater impacts on karst groundwater resources in a semi-arid environment by chloride mass balance methods. J. Hydrol. 2013, 502, 177-190. [CrossRef]

45. Palandačić, A.; Bonacci, O.; Snoj, A. Molecular data as a possible tool for tracing groundwater flow in karst environment: Example ofDelminichthys adspersusin Dinaric karst system. Ecohydrology 2012, 5, 791-797. [CrossRef]

46. Ojeda, L.; Vadillo, I.; Etiope, G.; Benavente, J.; Liñán, C.; del Rosal, Y.; Tapia, S.T.; Moríñigo, M.Á.; Carrasco, F. Methane sources and sinks in karst systems: The Nerja cave and its vadose environment (Spain). Geochim. Cosmochim. Acta 2019, 259, 302-315. [CrossRef]

47. Webster, K.D.; Drobniak, A.; Etiope, G.; Mastalerz, M.; Sauer, P.E.; Schimmelmann, A. Subterranean karst environments as a global sink for atmospheric methane. Earth Planet. Sci. Lett. 2018, 485, 9-18. [CrossRef]

48. McDonough, L.K.; Iverach, C.P.; Beckmann, S.; Manefield, M.; Rau, G.C.; Baker, A.; Kelly, B.F.J. Spatial variability of cave-air carbon dioxide and methane concentrations and isotopic compositions in a semi-arid karst environment. Environ. Earth Sci. 2016, 75, 8. [CrossRef]

49. Swaffer, B.A.; Holland, K.L.; Doody, T.M.; Li, C.; Hutson, J. Water use strategies of two co-occurring tree species in a semi-arid karst environment. Hydrol. Process. 2014, 28, 2003-2017. [CrossRef]

50. LeGrand, H.E. Hydrological and ecological problems of karst regions: Hydrological actions on limestone regions cause distinctive ecological problems. Science 1973, 179, 859-864. [CrossRef]

51. Trofimova, E. Towards an international protection system for karst environments background. Z. Geomorphol. 2016, 60, 3-15. [CrossRef]

52. Kresic, N.; Papic, P.; Golubovic, R. Elements of groundwater protection in a karst environment. Environ. Geol. Water Sci. 1992, 20, 157-164. [CrossRef]

53. Fahimnia, B.; Sarkis, J.; Davarzani, H. Green supply chain management: A review and bibliometric analysis. Int. J. Prod. Econ. 2015, 162, 101-114. [CrossRef] 
54. Mao, G.; Huang, N.; Chen, L.; Wang, H. Research on biomass energy and environment from the past to the future: A bibliometric analysis. Sci. Total Environ. 2018, 635, 1081-1090. [CrossRef] [PubMed]

55. Vain, P. Trends in GM crop, food and feed safety literature. Nat. Biotechnol. 2007, 25, 624-626. [CrossRef]

56. Aleixandre-Benavent, R.; Aleixandre-Tudó, J.L.; Castelló-Cogollos, L.; Aleixandre, J.L. Trends in global research in deforestation. A bibliometric analysis. Land Use Policy 2018, 72, 293-302. [CrossRef]

57. Kitchenham, B.; Pretorius, R.; Budgen, D.; Pearl Brereton, O.; Turner, M.; Niazi, M.; Linkman, S. Systematic literature reviews in software engineering-A tertiary study. Inf. Softw. Technol. 2010, 52, 792-805. [CrossRef]

58. Petersen, K.; Vakkalanka, S.; Kuzniarz, L. Guidelines for conducting systematic mapping studies in software engineering: An update. Inf. Softw. Technol. 2015, 64, 1-18. [CrossRef]

59. Marcos-Pablos, S.; García-Peñalvo, F.J. Technological Ecosystems in Care and Assistance: A Systematic Literature Review. Sensors 2019, 19, 708. [CrossRef]

60. García-González, A.; Ramírez-Montoya, M.-S. Systematic Mapping of Scientific Production on Open Innovation (2015-2018): Opportunities for Sustainable Training Environments. Sustainability 2019, 11, 1781. [CrossRef]

61. Chen, C. Searching for intellectual turning points: Progressive knowledge domain visualization. Proc. Natl. Acad. Sci. USA 2004, 101 (Suppl. 1), 5303-5310. [CrossRef]

62. Stefanowski, J.; Weiss, D. Carrot2 and Language Properties in Web Search Results Clustering; Springer: Berlin/Heidelberg, Germany, 2003; pp. 240-249.

63. Van Eck, N.J.; Waltman, L. Software survey: VOSviewer, a computer program for bibliometric mapping. Scientometrics 2010, 84, 523-538. [CrossRef] [PubMed]

64. Zastrow, M. Data visualization: Science on the map. Nature 2015, 519, 119-120. [CrossRef] [PubMed]

65. Ford, D.; Williams, P. Karst Hydrogeology and Geomorphology; John Wiley Sons, Ltd.: Chichester, UK, 2007.

66. Bakalowicz, M. Karst groundwater: A challenge for new resources. Hydrogeol. J. 2005, 13, 148-160. [CrossRef]

67. Ford, D.C.; Williams, P.W. Karst Geomorphology and Hydrology; Unwin Hyman Press: London, UK, 1989.

68. White, W.B. Karst hydrology: Recent developments and open questions. Eng. Geol. 2002, 65, 85-105. [CrossRef]

69. Dreybrodt, W. Principles of Early Development of Karst Conduits Under Natural and Man-Made Conditions Revealed by Mathematical Analysis of Numerical Models. Water Resour. Res. 1996, 32, 2923-2935. [CrossRef]

70. Kaufmann, G.; Braun, J. Karst Aquifer evolution in fractured, porous rocks. Water Resour. Res. 2000, 36, 1381-1391. [CrossRef]

71. Fairchild, I.J.; Borsato, A.; Tooth, A.F.; Frisia, S.; Hawkesworth, C.J.; Huang, Y.; McDermott, F.; Spiro, B. Controls on trace element $(\mathrm{Sr}-\mathrm{Mg})$ compositions of carbonate cave waters: Implications for speleothem climatic records. Chem. Geol. 2000, 166, 255-269. [CrossRef]

72. Yuan, D.X. Modern Karstology; Science Press: Beijing, China, 2016; pp. 323-326. (In Chinese) 